\title{
Self-Ignition Temperatures of Combustible Liquids
}

\author{
Nicholas P. Setchkin*
}

\begin{abstract}
The methods previously used for determination of the ignition temperatures of liquidsare briefly reviewed, and the large discrepancies in reported values noted. Various factors which affect the determined values of ignition temperature are discussed. A practical ignition apparatus consisting in part of an insulated spherical flask, designed to provide conditions favorable to low ignition temperature values, is described, and data obtained with this apparatus on a considerable number of combustible liquids are presented. The usefulness of time-temperature curves of a thermocouple junction placed in mixtures of combustible liquid and air, as a means of studying the preignition reactions in such mixtures is iliustrated.
\end{abstract}

\section{Introduction}

The fire hazards associated with the use, storage, and shipment of combustible liquids are so familiar as to need no discussion, and the tremendous and varied consumption of such liquids carries the problem of protection against these hazards into every element of modern economy. For the development of effective protective measures, as well as for efficient use of these liquids, extensive and accurate knowledge of their ignition characteristics is highly important.

Although standard definitions and methods of determination have been established for many of the physical and chemical properties of materials, such as density, viscosity, solubility, etc., there has been no general agreement on the definition or determination of ignition temperature. Consequently, determinations of this quantity by different investigators have varied widely both in numerical value and significance, with much resultant confusion and difficulty in the interpretation and practical application of the information.

Preparatory to the experimental work reported in this paper a study was made of the various methods previously employed for the determination of ignition temperature. It appeared that, although the ignition characteristics of a material were doubtless a function of some actual property of the material, the measurement of that property by any means readily available would be greatly affected by the ambient conditions. Hence, any practical definition of ignition temperature which might be adopted must continue to be based on a careful definition and standardization of the test apparatus and procedure. It was further concluded that a criterion that indicated the lowest temperature producing self-ignition of the material under conditions as favorable as might normally occur, would be the most useful in the practical analysis and elimination of hazards, and would also provide a suitable basis for data of research interest.

Accordingly, the apparatus and test procedure described in this paper were designed to determine values in the lower temperature range in which ignition may be possible. The method developed appears well suited to the purpose, and in tests of a large number and variety of materials it has given

\footnotetext{
*Present address, Library of Congress, Washington 25, D. C.
}

results of satisfactory reproducibility. The present paper covers the work carried out over a period of about 15 years on a considerable number of commonly used combustible liquids.

\section{General Considerations}

\subsection{Previous Determinations of Ignition Temperature}

Most of the methods that have been used in the determination of ignition temperature may be grouped into two general types, the "rising-temperature" method, and the "constant-temperature" method. In the former, a combustible mixture is introduced into the ignition apparatus, and its temperature is then continuously increased until positive evidence of ignition is observed. The self-ignition temperature is usually taken as the point at which the time-temperature curve for the material shows a definite increase in slope or as the point of intersection between the time-temperature curve for the material and that for the heating medium [1]. ${ }^{1} \quad$ In the constant-temperature method of determination, the ignition apparatus is preheated to a selected initial constant temperature before the specimen is introduced, and no adjustment of heat input to the apparatus is made after introduction of the specimen. The test is repeated with fresh specimens at different initial temperatures until the lowest temperature at which ignition is produced has been established. It has been determined as the temperature of the heating bath surrounding the reaction chamber, as the temperature of the combustion chamber wall, or as the temperature of the air within the chamber.

Within these two general approaches to the problem, numerous and diverse methods of determination have been developed (C. R. Brown [2] gives references to 16 different methods of the rising temperature type alone). Following are brief outlines of a number of procedures that have been used, and the data in tables 1 and 2 illustrate the wide variation in values obtained by different investigators.

Oil-drop method. Early determinations of ignition temperature with the so-called "oil-drop method" were made by Holm [3] in 1913 with a heated

\footnotetext{
1 Figures in brackets indicate the literature references at the end of this paper.
} 
TABLE 1. Ignition temperature (in degrees centigrade) of various combustible liquids determined with oil-drop method [7

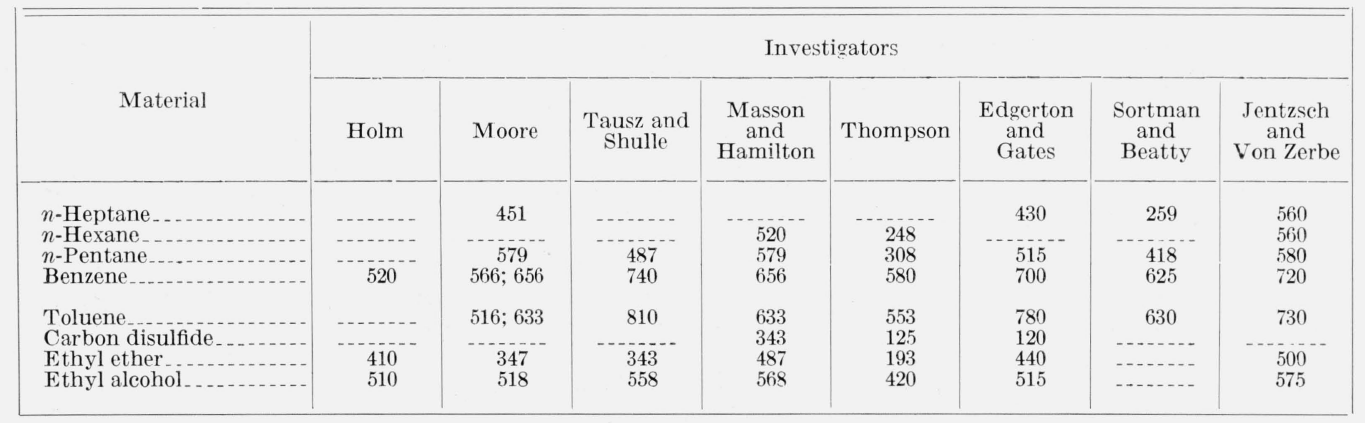

TABLE 2. Ignition temperature (in degrees centigrade) of liquids determined with different methods [15]

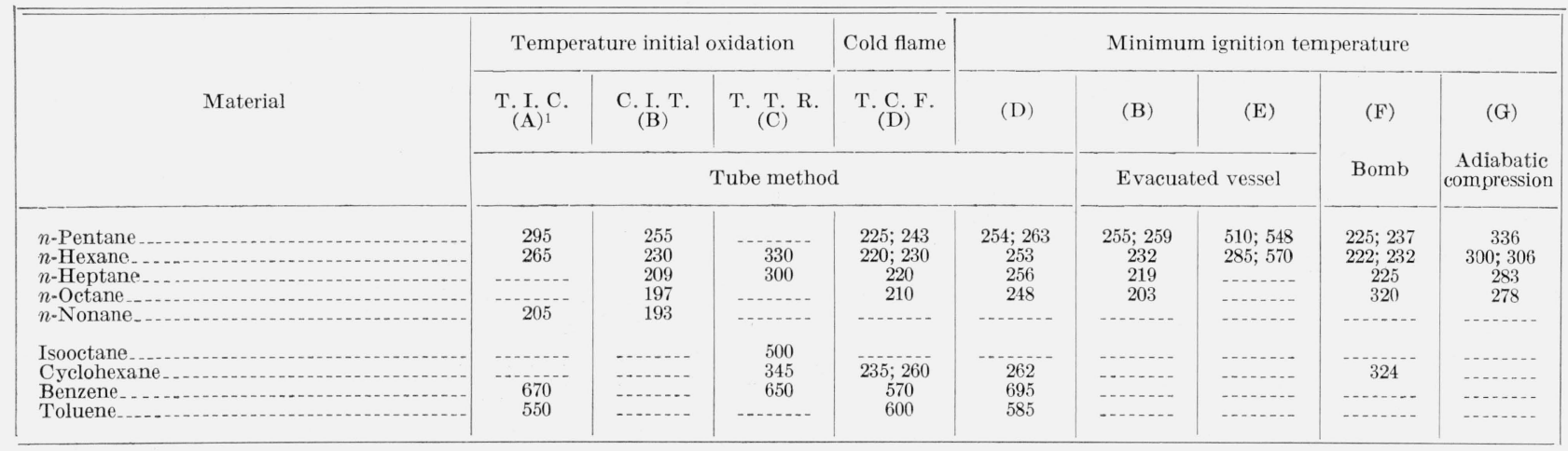

${ }^{1}$ Investigators: (A) Callendar; (B) Lewis; (C) Estradere; (D) Prettre; (E) Townend and Cohen; (F) Dumanois and others; (G) Tizard and Pye.

porcelain surface. Moore [4] used a platinum crucible submerged in molten metal or embedded in a steel block. Sortman and Beatty [5] made a small cvlindrical cavity of $43-\mathrm{ml}$ capacity in a stainlesssteel block and provided for the circulation of preheated air. Jentzsch and Von Zerbe [6] also used a steel block with four cylinders $(7.1 \mathrm{ml})$ and circulation of oxygen or air. A modified type of the Moore apparatus, heated electrically, has been widely used by many investigators [7]. The initial temperature of the bath, or wall of the ignition vessel, leading to ignition is usually considered as the selfignition temperature. The values given in table 1 are reproduced from reference [7].

Dynamic tube method. In this method, a Pyrex tube is heated in a conventional electric furnace to the desired temperature indicated by a thermocouple in contact with the outside surface of the tube. A combustible substance, being preheated separately or together with air or oxygen, is allowed to pass through the tube. The tests are repeated at different temperatures of the tube until evidence of ignition is observed. Apparatus of this type was used by Dixon and Coward in 1909 and 1934 [8, 9], by Mason and Wheeler [10], and by many others. Dixon and Coward limited their test to 15 seconds. Callendar [11] and Moureu [12] made a study of slow combustion and determined the "Temperature of Initial Combustion" (T. I. C.) in an improved apparatus. This temperature was defined as the tube temperature necessary to provide the first appearance of products of combustion (steam, carbon dioxide, aldehyde, etc.) and was determined by chemical analysis of samples taken periodically during various phases of the reaction.

This temperature has some relation to the "Temperature of Thermal Reaction" (T. T. R.) introduced by Estradére [13], and the "Critical Inflection Temperature" (C. I. T.) introduced by Lewis [14]. All these temperatures are related to the "Temperature of Initial Oxidation" [15] or, in other words, to the temperature of incipient self-heating. Prettre deifned the ignition temperature by means of two criteria, the appearance of "cold flame" (T. C. F.) and the appearance of normal flame at "Minimum Ignition Temperature" (M. I. T.). A tabulation of ignition temperatures measured by this method is included in table 2, which is reproduced from reference [15].

Evacuated-vessel method. In this method a combustible mixture is suddenly admitted into an evacuated vessel preheated to the desired temperature. This method was originated by Mallard and Le Chatelier in 1880 and was used subsequently by Mason and Wheeler [10] and Townend [16]. Ignition was indicated by rapid rise in pressure. Lewis and also Pidgeon and Egerton [17] modified this method by admission of the cold combustible mixture into an evacuated vessel heated at a steady rate (rising-temperature method).

Bomb method. The bomb method was used by Neumann [18] and other investigators for determination of the ignition temperatures of combustible mixtures at high pressures. 
Adiabatic compression method. Heating of a combustible mixture to the ignition point by adiabatic compression was used by Tizard and Pye [19] and Pignot [20]. It is hardly likely that ignition temperatures measured by this method, which involves the use of rising temperature and pressure, are directly comparable to those measured at constant pressure.

ASTM standard method. Committee $\mathrm{D}-2$ on Petroleum Products and Lubricants of ASTM in 1930 adopted a standard method and apparatus (D286-30) [21] for the determination of the "Autogeneous Ignition Temperature." The standard apparatus consists of a conical Pyrex flask of 160-ml capacity, submerged in molten solder heated by a gas burner. A few drops of the liquid to be tested are allowed to fall into the flask, previously heated to different initial temperatures. The ignition temperature is defined as the lowest temperature of the solder bath, indicated by a thermocouple placed in a silica protection tube submerged in the bath near the flask, necessary to cause ignition of the specimen.

\subsection{Selection of Method and Definition of Self- Ignition Temperature}

With the rising-temperature procedure of determination, the ignition temperatures vary with the rate of temperature rise and with the criterion of ignition. Elaborate control equipment is necessary to obtain reproducible results either on the basis of a fixed rate of heating or on that of maintaining a fixed temperature difference between any part of the specimen and its surroundings. Furthermore, the comparatively slow heating of the specimen in this method is not generally well suited to the study of liquids, many of which apparently produce vapors that form relatively stable compounds with oxygen at low temperatures. If the system has time in a low-temperature range to permit the formation of such compounds in appreciable amount, the observed ignition temperature may be well above that which might have been obtained with the constant-temperature method. In this latter method, on the other hand, precise control of the initial temperature may be accomplished with relatively simple equipment, and the rapid heating of the specimen limits the time in which low-temperature reactions may take place. The constant-temperature method of determination was selected for the present work, and the liquid charge was sprayed into the heated chamber as a fine dispersion, so that it rapidly became vaporized and mixed throughout the air in the chamber.

The characteristic thermal effects when a combustible liquid is thus introduced into the chamber at different initial temperatures are illustrated by the time-temperature curves of figure 1. After injection of the dispersed charge, the temperature within the chamber first falls below the initial temperature because heat is absorbed in vaporizing and heating the sample. In a short time, heat supplied mainly from the walls of the chamber reestablishes the initial

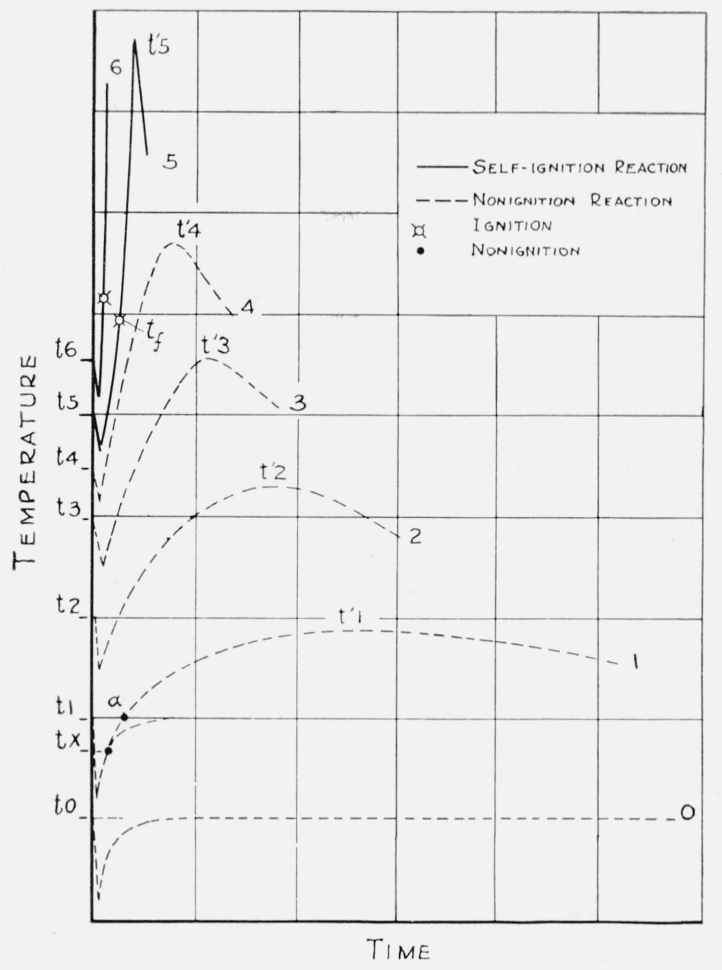

FiguRE 1. Idealized time-temperature curves for self-ignition and nonignition reactions of combustible liquids.

temperature. At relatively low initial temperatures, there may be no further thermal effects, and the temperature of the sample-air mixture may remain constant at the initial value, as at $\mathrm{t}_{0}$. At higher initial temperatures, exothermic reactions within the sample-air mixture may be induced and the temperature of the reaction mixture raised above the initial value. The extent of this temperature rise depends upon the difference between the rate of heat generation within the mixture and the rate of heat loss to the chamber walls. At initial temperatures that produce relatively mild reaction within the mixture, the heat generated is eventually lost through the chamber walls without visible effect on the mixture, and the temperature returns to the initial value after a period of time dependent on the intensity of the exothermic reaction. This situation is illustrated by initial temperatures $t_{1}, t_{2}, t_{3}$, and $t_{4}$ in figure 1 . However, at some temperature, characteristic of the material under study and of the particular test chamber employed, the reaction within the mixture will become sufficiently intense to raise the temperature to the ignition point, as evidenced by flame or explosion. The initial temperatures $t_{5}$ and $t_{6}$ represent such ignition reactions and further illustrate the reduction in ignition lag, which usually results as the initial temperature is increased.

For the present study, the following definition of self-ignition temperature was adopted:

The self-ignition temperature (SIT) of a liquid is the minimum temperature from which a combustible mixture with air will pass into a condition of observable combustion in the experimental apparatus employed. 


\subsection{Factors Affecting the Observed Values of SIT}

\section{a. Thermal Characteristics of the Apparatus}

Inasmuch as ignition depends upon the temperature reached by the reacting mixture, the governing factor in its development is the amount of heat retained within the mixture and available for increasing the temperature. Hence, ignition will result only when the reaction is intense enough to generate heat more rapidly than it is lost from the reaction mixture to its surroundings, and the initial temperature of the chamber must be high enough to induce such a reaction. Therefore, the higher the rate of heat loss, the higher will be the initial temperature required to accelerate the reaction to ignition, that is, the higher will be the determined values of the SIT.

Thus, the design and construction of the reaction chamber affect the SIT values that will be obtained. In order for the determinations to approach the lowest temperatures from which there may be danger of ignition, the chamber walls should be constructed with as low heat capacity and heat conductivity as may be practicable. The size and shape of the chamber, as well as the structural materials, must also be considered.

\section{b. Pressure and Uniformity of Temperature}

The relation between the pressure within the ignition chamber and the observed value of the SIT has not been determined. However, for the development of a practical test method, it is reasonable to assume that atmospheric-pressure variations will have little effect on the determined values of the SIT.

It is probable that the ignition reaction between the combustible substance and the oxidizing agent initiates with the most highly energized molecules of the mixture, and supplies the heat necessary to raise the energy level of adjacent molecules to the ignition point, thus propagating itself throughout the mixture [22]. If all of the molecules present are very close to the required energy level at the same instant, the spread of ignition through the mass will be extremely rapid. Hence, the maintenance of uniform temperature throughout the reaction chamber will favor rapid propagation of the ignition reaction.

\section{c. Reaction Mixture Ratio}

The ratio of the combustible substance to air in the reaction mixture has an appreciable effect upon the SIT. Mixtures that are excessively rich or excessively lean usually ignite at higher temperatures than those close to some intermediate composition characteristic of the material. Carbon and soot, which may have been deposited from previous determinations with over-rich mixtures, may also influence the SIT value obtained.

\section{d. Method of Temperature Measurement}

Temperature measurements are usually made by means of one or more thermocouples either embedded in the heating bath or medium outside the chamber walls or installed directly inside the reaction chamber. Reproducible results may be obtained with any of these methods, but because heat loss from the chamber cannot be conveniently eliminated, lower values of SI'T are usually observed with the last arrangement. Furthermore, a thermocouple placed inside the chamber may also be used to indicate temperature changes during the reaction.

\section{e. Criteria of Ignition}

The intensity of the visual evidence of ignition varies decidedly with the initial temperature from which the reaction proceeds. At high initial temperatures, self-ignition usually occurs in more or less violent form, such as a bright flash of flame and audible expulsion of gases (explosion). At somewhat lower initial temperatures the flaming becomes relatively mild, whereas at the lowest temperature from which ignition is detected, the flame may be very dull violet or blue, often visible only under darkroom conditions. The latter may be confused with cool flame reaction, which is not generally recognized as evidence of ignition even when, occasionally, it is accompanied by a rapid rise in the temperature of the reaction mixture.

The time lag before the development of ignition is also affected by the initial temperature of the reaction. It is an inverse function of the initial temperature and may be only a fraction of a second at high initial temperatures and may amount to a number of minutes at the lowest temperature from which ignition occurs. For example, methyl cyclohexane showed an ignition lag of 30 seconds at $275^{\circ} \mathrm{C}$, and, using the same test equipment, the lag was $20 \mathrm{~min}$ $10 \mathrm{sec}$ at $248^{\circ} \mathrm{C}$. By limiting the tests to 10 or 15 seconds, as some investigators have done, the selfignition temperature would have been determined as well above $275^{\circ} \mathrm{C}$

In addition to the visual evidence of ignition, the time-temperature curves for many liquids provide supporting indication of its occurrence. The curves at $t_{5}$ and $t_{4}$ in figure 1 illustrate typical differences in the curves for ignition and nonignition reactions proceeding from only slightly differing initial temperatures. Although the rate of temperature rise was at first about the same in the two cases, it soon became much more rapid and pronounced in the ignition reaction and was followed by a sharper drop from the peak temperature. This decided difference in the time-temperature curves for ignition and nonignition reactions is often helpful in the final determination of the SIT, particularly when the detection of flame becomes difficult and somewhat uncertain.

\section{f. Extraneous Stimuli of Ignition}

The ignition reaction may be induced by a number of means extraneous to the reaction mixture itself, and devices used by various investigators have included pilot flames, sparks, detonators, overheated surfaces, and catalytic agents. The introduction of such stimuli is often accompanied by complex effects 
on other characteristics of the equipment, and in general it tends to complicate the problem of accurate interpretation and evaluation of the results. Until more extensive research has been carried out on problems related to their use, it would appear advisable to carefully avoid their introduction, either intended or incidental.

\section{Test Apparatus and Procedure}

\subsection{Development of Apparatus}

Preliminary experiments were conducted with the AS'TM standard ignition apparatus [21] with solder bath and gas burner. Because of difficulties in controlling the temperatures and poor reproducibility in the results, this apparatus was modified to include electric heating elements, a 0.2-liter spherical Pyrex flask, a stirring arrangement in the bath, and direct measurement of temperature in the flask. In order to reduce the heat loss from the reacting mixture to the surroundings and improve uniformity of temperature control in the flask, the solder bath was later replaced with two sets of heating elements made of nichrome wire, in asbestos sleeving, wound around the upper and lower halves of the spherical flask and protected with a refractory cement. The final design of the ignition apparatus consisted of a 1-liter spherical Pyrex flask, as shown in figure 2, placed concentrically inside a refractory casing so that a $1 / 2$-in. air space was provided between the flask and the casing for further reduction of heat loss. The heating wires were wound around the upper and lower halves of the casing and the neck, with independent temperature controls. Temperatures of the three heaters were indicated by three thermocouples made of chromel-alumel (26 B\&S gage) wire placed behind each group of heating coils. Two additional thermocouples were placed in contact with the upper and lower surfaces of the flask. The sixth thermocouple, insulated by glass sleeving

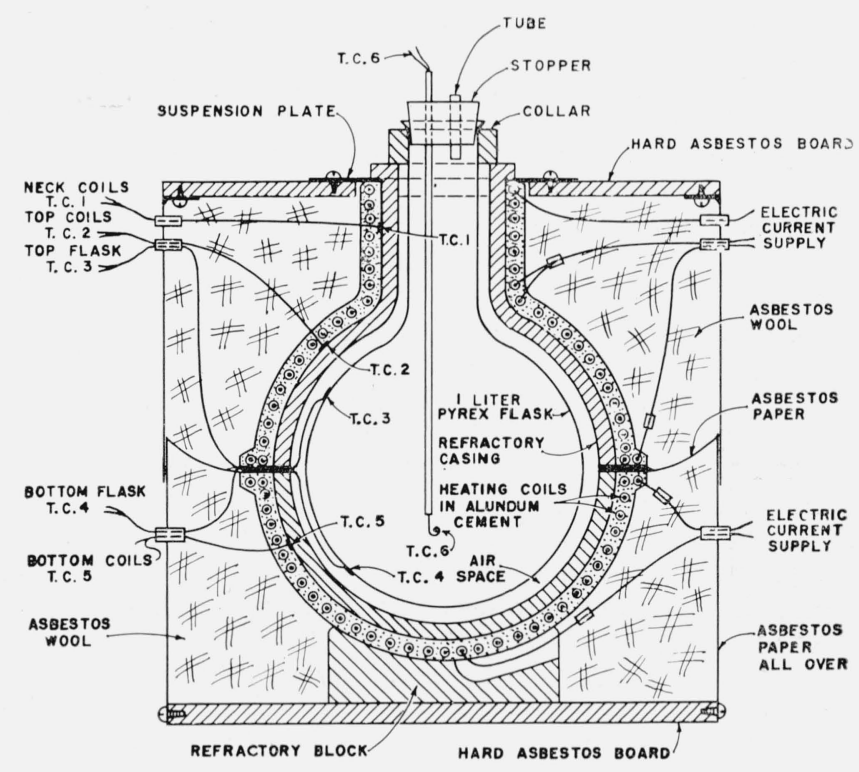

FIGURE 2. One liter spherical pyrex flask ignition apparatus for liquids with air space and refractory casing.

and also of 26 (B\&S gage) wire, was placed in the lower part of the flask for indicating the temperature inside the flask. The flask neck was closed with a cement-asbestos stopper having two passages, one for the thermocouple wires and the other for injection of the charge.

The effect of chamber size on the observed selfignition temperature was studied by means of additional test units of the following capacities: 0.008, $0.035,0.2,12$, and 15 liters. These units were constructed in substantially the same manner as shown in figure 2, with the exception of the 15-liter apparatus, the chamber walls of which were made of opaque silica about $3 / 8$ in. thick, with no air space between the walls and the heating coils. From the results shown in table 3 and figure 5 it is evident that, over

TABLE 3. Effect of flask size on ignition characteristics

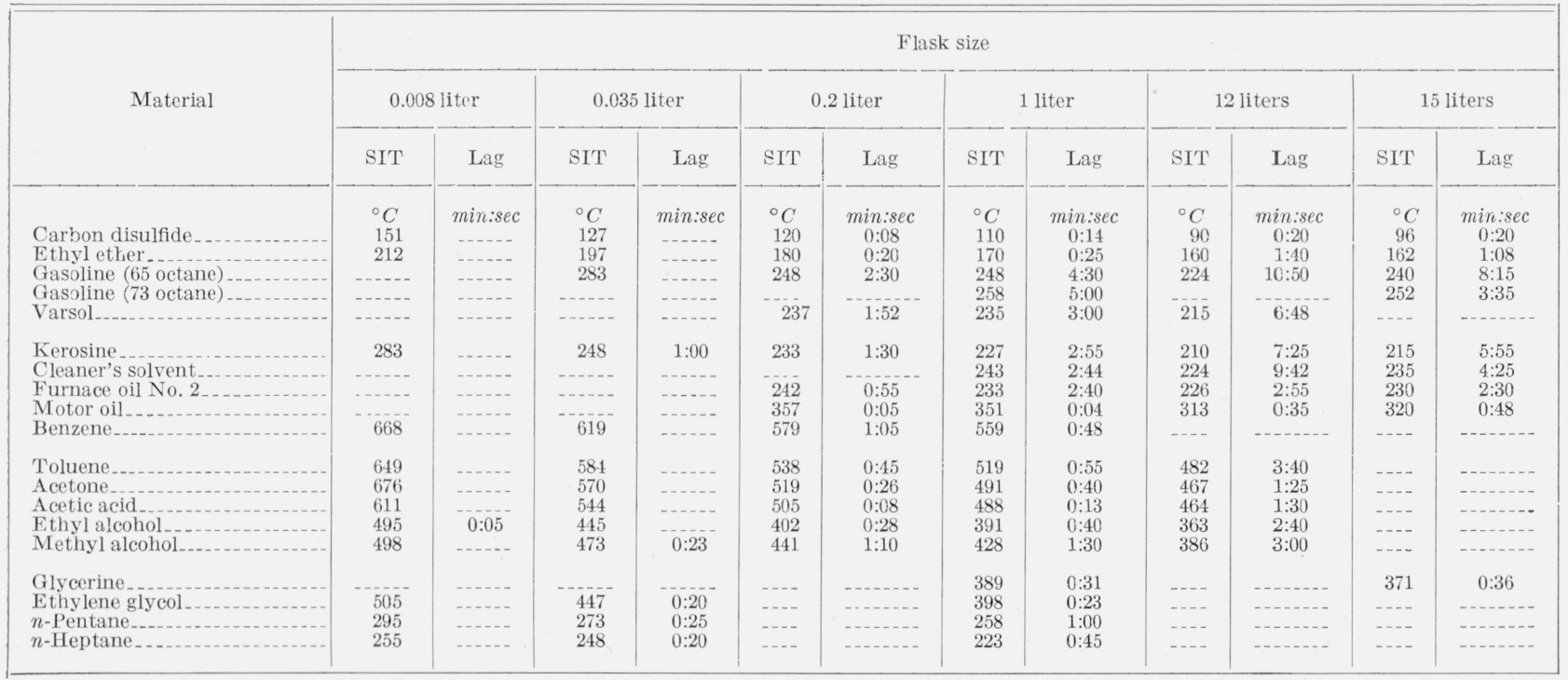


the size range studied, the observed self-ignition temperature becomes lower with increasing chamber size in units of similar construction. This effect should not be unexpected as the rate of heat loss per unit volume from the reacting mixture will be smaller with the larger chambers because of the smaller ratio of surface to volume. The higher values of SIT obtained with the 15 -liter unit than with the 12-liter unit indicate a greater heat loss to the thicker opaque silica walls. Although slightly lower SI'T values were obtained with the 12-liter Pyrex unit, it was unwieldy and fragile. Consequently, the standard, easily replaceable 1-liter flask was used as the more practical test apparatus, in making most of the determinations.

An investigation was also made of the comparative SIT values obtained with different types of casing around the 1-liter flask. In addition to the refractory casing separated from the flask by a $1 / 2$-in. air space shown in figure 2, two other units were constructed. In one of these a $5 / 8$-in.-thick copper casing was iitted as closely as possible around the flask, and in the other, a refractory casing with mirrored inner surface was separated from the flask by a $5 / 8$-in. air space. The results obtained with several different liquids tested in these three units are shown in table 4. In each case the highest value of SIT was obtained when using the metal-encased flask, whereas the lowest value was obtained with the mirrored refractory casing. However, it appeared that the mirror coating on the refractory casing would not hold up

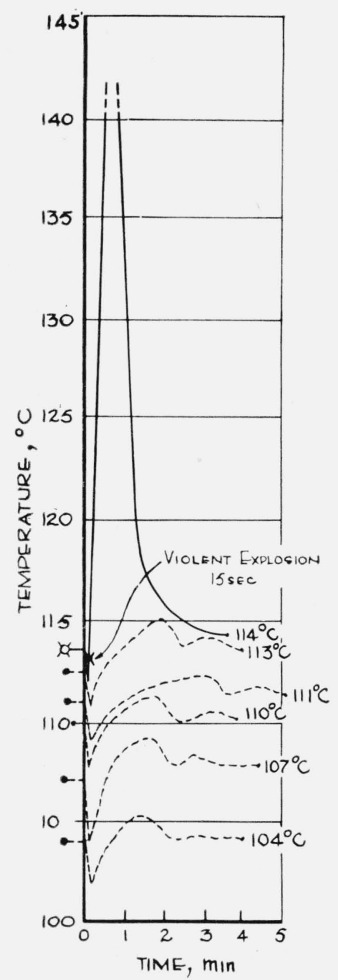

Figure 3. Time-temperature curves for carbon disulfide. 1-liter flask, charge equals $0.5 \mathrm{ml}$ well at high temperatures and would be subject to variable deterioration with repeated use. As it is important that the thermal characteristics of the apparatus remain as constant as possible, the simple refractory casing was selected for the major portion of the work.

TABLE 4. Effect of chamber wall construction on self-ignition temperature with the 1-liter flask

\begin{tabular}{|c|c|c|c|}
\hline \multirow{2}{*}{ Liquids } & \multicolumn{3}{|c|}{ Type of casing } \\
\hline & Metal & Refractory & $\begin{array}{l}\text { Mirror } \\
\text { surface }\end{array}$ \\
\hline $\begin{array}{l}\text { Acetic acid } \\
\text { Acetone } \\
\text { Ethyl alcohol } \\
\text { Gasoline (motor) } \\
\text { Isooctane } \\
\text { Toluene } \\
\text { Varsol } \\
\text { Ethyl ether }\end{array}$ & $\begin{array}{l}{ }^{\circ} \mathrm{C} \\
501 \\
505 \\
405 \\
249 \\
431 \\
529 \\
237 \\
172\end{array}$ & $\begin{array}{l}{ }^{\circ} \mathrm{C} \\
488 \\
491 \\
391 \\
243 \\
420 \\
519 \\
235 \\
170\end{array}$ & $\begin{array}{c}{ }^{\circ} \mathrm{C} \\
474 \\
385 \\
238 \\
409 \\
234 \\
-\ldots\end{array}$ \\
\hline
\end{tabular}

The possibility that the thermocouple wires might exert some catalytic effect on the reaction was seriously considered. A test apparatus was carefully prepared so that heat losses by conduction were practically eliminated. Comparative tests were conducted, with the thermocouple remaining in its usual position in the chamber throughout the reaction, and with the thermocouple removed from the chamber just before injection of the liquid charge. The self-ignition temperature was a little higher with the thermocouple present than without it, and increased slightly as the length of the wire in the chamber was increased, but no evidence of catalytic action was detected.

Callendar [23] conducted experiments on the possible catalytic influence of a variety of metals placed in a test tube and, of those studied, only platinum black showed catalytic action. Thompson [24], and Matson and Dufour [25], used different metals for construction of the entire wall of the reaction chamber. Definite variation of the selfignition temperature with the metal used was found, but the effects were evidently related to the heat losses to and through the container walls.

\subsection{Test Procedure}

The procedure followed in establishing the selfignition temperature of a combustible material consisted of a series of experiments at different temperatures and with different proportions of combustible material and air. In conducting an experiment, the power supplied to the individual heating elements of the ignition apparatus was adjusted until the temperature inside the flask was uniform to $2 \mathrm{deg} C$ and constant at some value estimated to be near the SIT. A charge of $0.2 \mathrm{ml}$ of the combustible liquid per liter of flask volume was injected into the flask by means of a hypodermic syringe fitted with a fine needle. This provided the dispersion necessary for rapid evaporation and nearly simultaneous initiation of the reaction throughout the flask. The 
reaction was permitted to proceed without any alterations of the power supplied to the apparatus.

In order to follow the nature of the reaction, observations of the electromotive force of the thermocouple inside the flask, at intervals of 15 to 20 seconds, were plotted against time as the reaction proceeded. The temperatures of the heating coils and flask surface were checked at intervals of 3 to 5 minutes.

The experiment was repeated at different initial temperatures until the lowest temperature from which ignition occurred was determined for the charge of $0.2 \mathrm{ml}$ of combustible material per liter of air. Additional experiments were then made with different charges to establish the lowest temperature from which the optimum ratio of combustible material to air would proceed to ignition.

Generally, ignition was clearly indicated by audible or visible evidences (explosion, puff, flame), and it was also shown by characteristic changes in the timetemperature curves, which served as dependable criteria when the visible evidence became uncertain or obscured. As an aid to visual detection in the final determinations, the interior of the reaction flask was viewed under dark room conditions by means of a mirror placed above the flask opening. Under these conditions, even very weak flames were distinctly visible, and flames obscured by the production of dense smoke and fumes could be detected from the illumination of the fumes.

Materials such as gums, waxes, and tars, which were too viscous at room temperature to be handled by syringe injection, were tested by placing them in a small crucible suspended in the lower part of the flask by a thin wire. This crucible arrangement was also used for at least the preliminary tests on certain oils, lacquers, and paints, which produced especially sooty residues, because it helped to prevent an excessive accumulation of soot on the walls of the flask. It was necessary, however, to make a correction for the cooling effect of the crucible, on any SIT values obtained in this way.

After each test, the products of decomposition were blown out of the flask by a jet of air in order to reduce the amount of carbon or soot deposited on the walls. The interior flask surface was cleaned at regular intervals during the preliminary tests for approximate determinations of the SIT, and before each test in the final determinations.

\section{Test Results}

The following ignition characteristics were determined under the specified test conditions for a number of combustible liquids:

1. Self-ignition temperature.

2. Character and intensity of the evidence of ignition.

3. Favorable fuel-air mixture ratio for minimum ignition temperature.

4. Time-temperature curves and ignition lags for different initial temperatures.

Values for the SIT given in tables 3 to 9 are the minimum values obtained under the most favorable conditions for ignition of the particular material. Representative characteristics and time-temperature curves for the materials under study are shown in figures 3 to 22 , but they do not in all cases include the determination that gave the lowest SI'T value. Some minor discrepancies will therefore be observed between the SI'T values in the tables and those shown by the curves.

For convenience, the combustible materials studied in this investigation have been grouped as follows:

1. Liquids of low ignition temperature.

2. Common petroleum products.

3. Petroleum compounds.

4. Reference fuels.

5. Miscellaneous compounds.

6. Miscellaneous commercial materials.

\subsection{Liquids of Low Ignition Temperature}

The ignition characteristics of two liquids, carbon disulfide and ethyl ether, ignitible at comparatively low temperatures are given in table 3 .

\section{a. Carbon Disulfide}

The self-ignition of carbon disulfide was usually indicated by a violent explosion accompanied by flame and a very rapid rise in temperature (see fig. 3). The preignition reaction, however, was of a very mild form, indicated by a gradual rise in tempera-

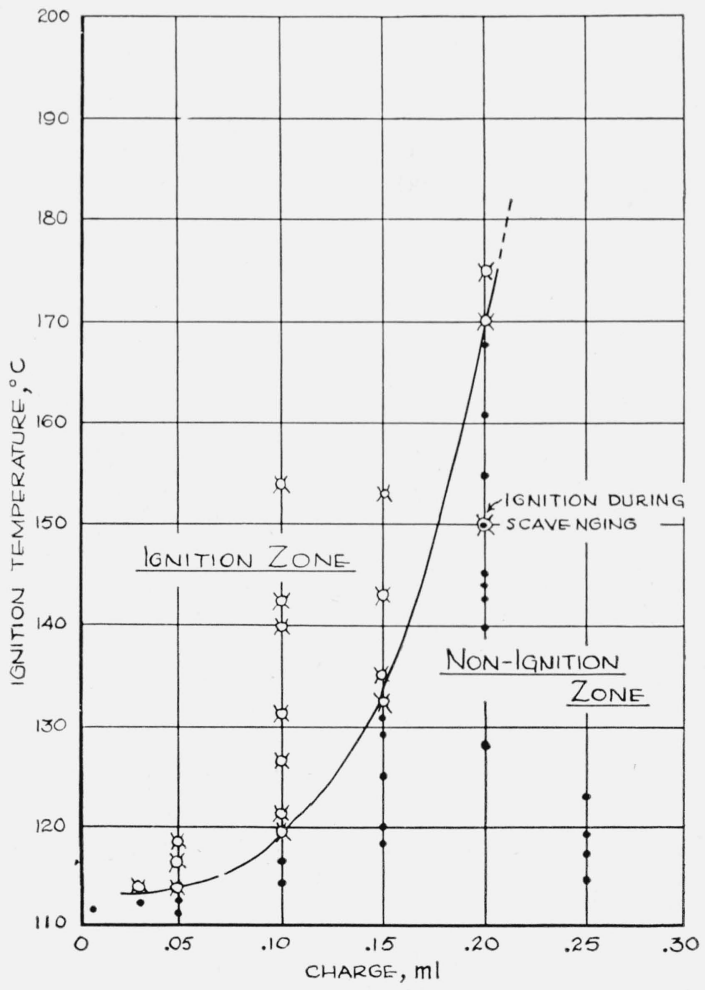

FIGURE 4. Effect of charge on ignition temperature of carbon disulfide.

1-liter flask 
ture, even for temperatures just below the ignition region. Minor fluctuations in the time-temperature curves sometimes resulted from secondary reactions caused by rich mixtures or by gases evolved from deposits on the flask surface if not cleaned before each test. Both of these factors may have a retarding effect on the ignition reaction. Normally the lowest self-ignition temperatures for combustible liquids were observed when using charges of 0.2 to $0.25 \mathrm{ml}$ per liter of air. However, self-ignition temperatures of carbon disulfide showed a rapid drop as the fuel charge was reduced from 0.2 to 0.05 $\mathrm{ml} /$ liter of air and remained almost constant for charges below $0.03 \mathrm{ml}$, as shown in figure 4 .

The carbon disulfide-air mixture had one critical ratio for each initial temperature, above which the mixture remained nonignitible. For example, the critical charge for the initial temperature of $150^{\circ} \mathrm{C}$ was about $0.18 \mathrm{ml}$. With a charge of $0.25 \mathrm{ml}$, the reaction was not accelerated to ignition during the $2 \frac{1}{2}$-min test period. If a fresh charge of air was admitted at the end of this nonignition reaction, a violent ignition occurred. This ignition probably resulted from reducing the concentration of the mixture below the critical value of $0.18 \mathrm{ml}$ per liter.

\section{b. Ethyl Ether}

Self-ignition of ethyl ether was characteristically indicated by a violent explosion accompanied by a large flame and rapid rise in temperature. Typical time-temperature curves are shown in figure 5 for different sizes of ignition chambers.

The nonignition reaction of this liquid was characterized by a slow rise of temperature for a considerable time after injection of the charge. During the first period of the exothermic reaction, extending from 5 to 10 seconds, the pressure inside the flask increased slightly and gases were expelled

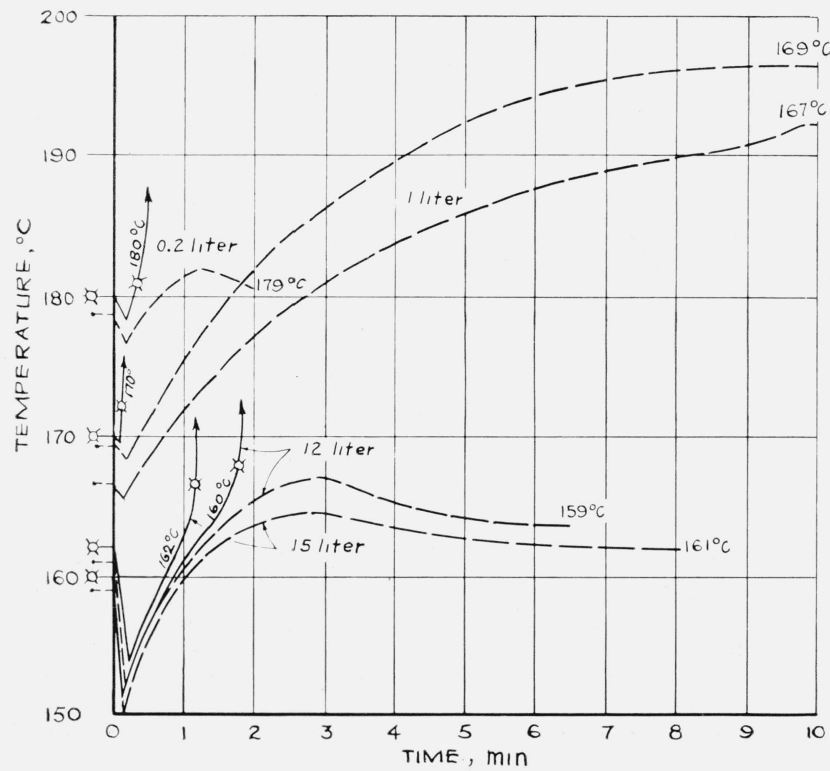

Figure 5. Effect of chamber size on SIT of ethyl ether. from the neck with a barely audible sound. The temperature of the mixture continued to rise and, in about 10 or $15 \mathrm{~min}$, reached its maximum (25 deg $\mathrm{C}$ above the initial temperature). However, at slightly higher initial temperatures ignition occurred at a time when the thermocouple indicated a lower temperature of the mixture than the maximum observed in the preceding test. This fact seemed to indicate that either the development of ignition is not a simple function of gas temperature or the thermocouple and temperature-indicating system could not accurately follow the rapid temperature changes at the point within the gas where ignition actually took place.

\subsection{Common Petroleum Products}

The ignition characteristics of 18 common petroleum products were determined, and the final SIT values obtained are given in table 5 .

TABLE 5. Ignition characteristics of common petroleum products determined in the 1-liter flask

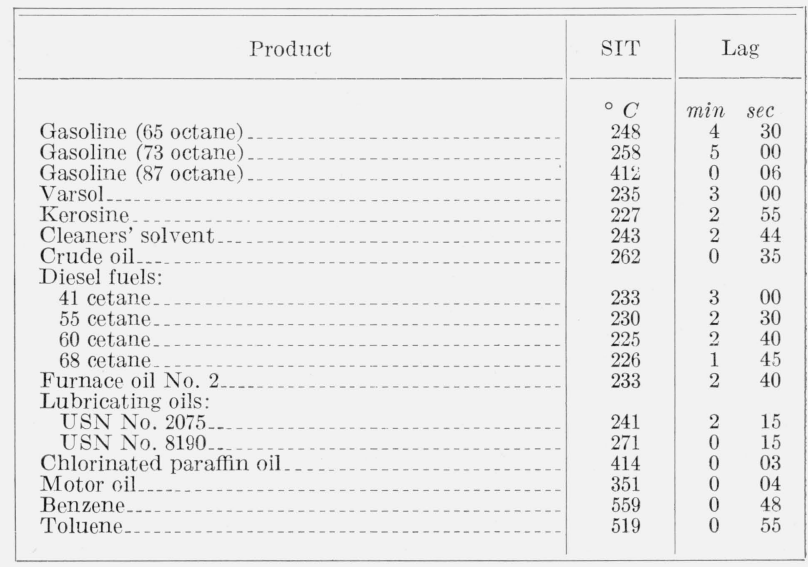

\section{a. Motor Gasoline}

The time-temperature curves for motor gasolines were characteristic of a number of refined petroleum products and differed from those of combustible liquids of nonpetroleum origin. The exothermic reaction appeared to proceed in two stages. It was characterized by a consistently reproducible temporary drop in temperature as the reaction progressed, probably caused by an interruption of the exothermic reaction or the occurrence of some endothermic process. The time-temperature curves of figure 6 show this two-stage reaction, the characteristics of which were not appreciably altered by varying the charge or the size of the flask. Ignition of gasoline usually occurred during the last stage of the reaction, whereas that of kerosine and cleaner's solvent occurred in the first stage.

A comparison of adjacent ignition and nonignition curves suggests that the rate of formation of stable compounds was highly sensitive to slight variations in temperature. Not only did the temperature in 


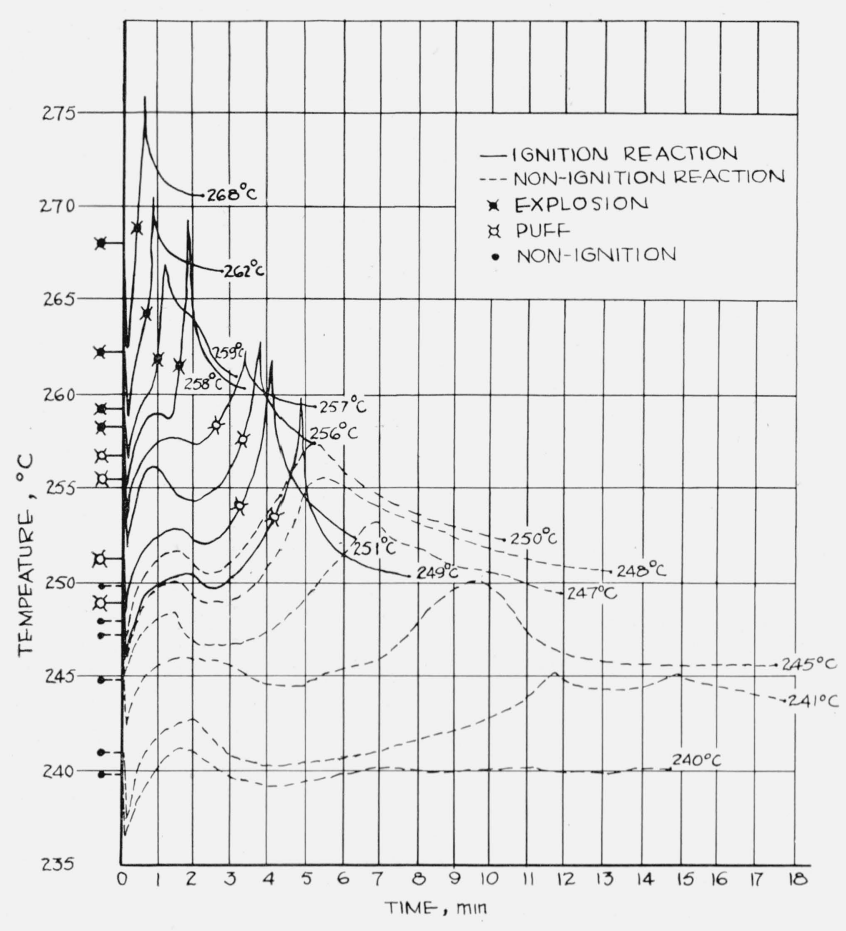

Figure 6. Time-temperature curves for 65 octane motor gasoline.

1-liter flask, charge equals $0.2 \mathrm{ml}$.

the nonignition reaction rise well above the SIT, but the reaction mixture had become so stable that it was not ignitible either by spark or flame, or by additional heating up to $400^{\circ} \mathrm{C}$, unless diluted with fresh air.

The intensity of the evidence of ignition varied with the initial temperature. From initial temperatures close to the SIT, gasolines of high octane number tended to ignite with a dull blue flame observable under dark-room conditions, and gasolines of low octane number generally ignited with a mild orange flame accompanied by audible expulsion of gases ("puff"). Ignition at higher initial temperatures was usually indicated by a more violent flash of flame or by audible expulsion of gases. It was noted also that ignition from high initial temperatures left the surface of the flask more heavily coated with soot and combustion products than did ignition from lower initial temperatures.

Ignition lag was found to be closely correlated with the ignition temperature, as shown in figure 7. The lowest self-ignition temperature was usually determined from tests conducted with different charges, as shown in figure 8.

\section{b. Other Gasolines and Varsol}

The ignition characteristics of other gasolines and Varsol were substantially the same as those of motor and aviation gasolines (supply of 1937), with a two-stage reaction and with ignition occurring in the second stage of reaction.

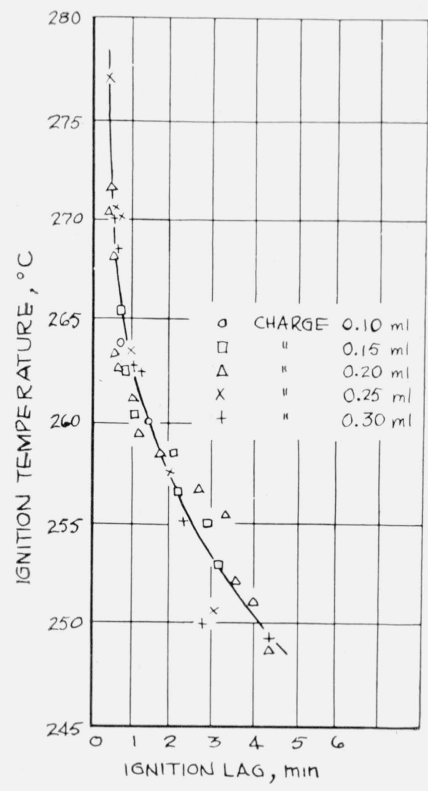

FIGURE 7. Relation between ignition lag and ignition temperature for motor gasoline.

1.liter flask.

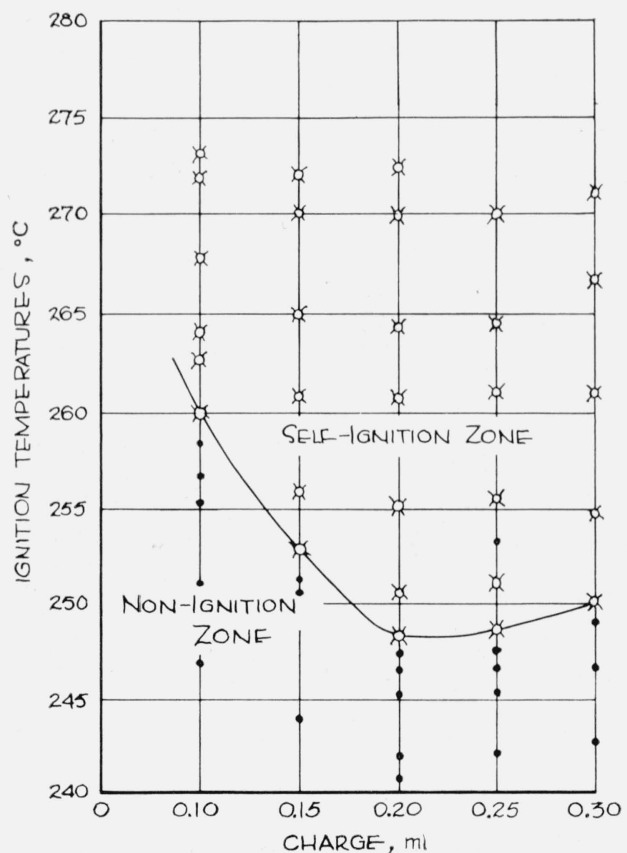

FiguRE 8. Effect of charge on ignition temperature of motor gasoline.

1-liter flask.

\section{c. Kerosine and Cleaner's Solvent}

Kerosine and cleaner's solvent belong to another group of petroleum products, the ignition of which seemed to occur during the first stage of reaction in spite of the fact that the nonignition reaction pro- 


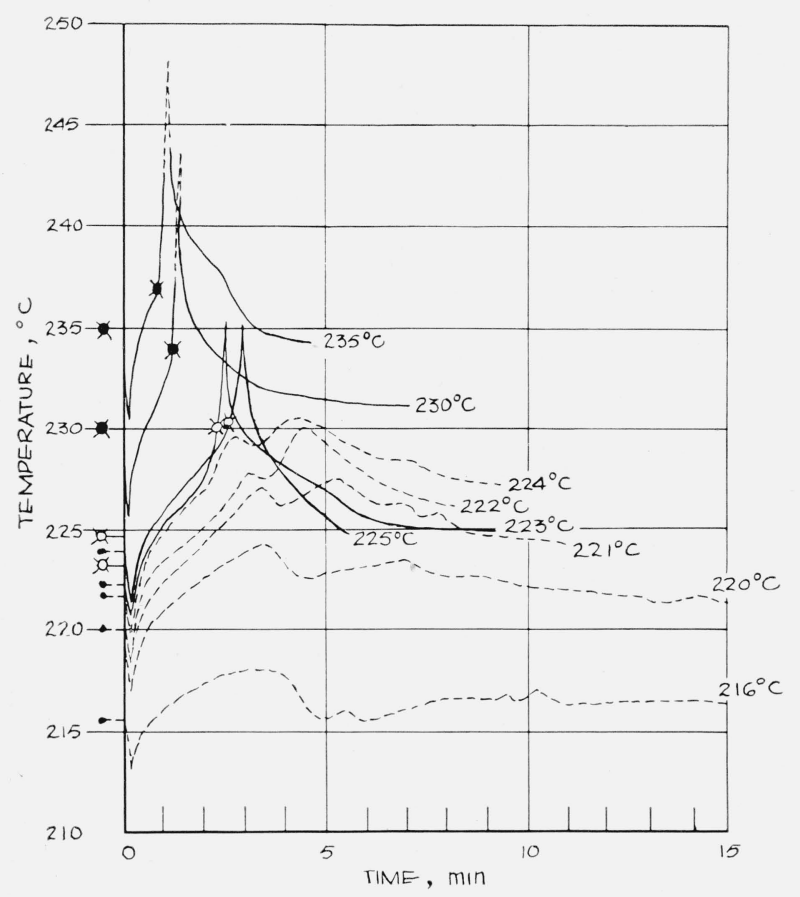

Figure 9. Time-temperature curves for kerosine. 1 -flask, charge equals $0.25 \mathrm{ml}$.

ceeded with a two-stage reaction. Typical timetemperature curves are shown in figures 9 and 10 . "After-burning" of cleaner's solvent in the region of high ignition temperatures was more pronounced than with other fuels, and ignition at all temperatures was indicated by mild flame and a barely audible expulsion of gases.

\section{d. Crude Oil}

Lagunillas crude oil of gravity 17 API, flashpoint $15^{\circ} \mathrm{C}$, and sulfur content 1.91 percent, was tested in connection with a study of the explosion of an oil tanker. The SIT of this oil was found to be $262^{\circ} \mathrm{C}$, with an ignition lag of 35 seconds. The ignition and nonignition reactions proceeded in a one-stage pattern, in contrast with the two-stage reactions of the gasoline and kerosine groups.

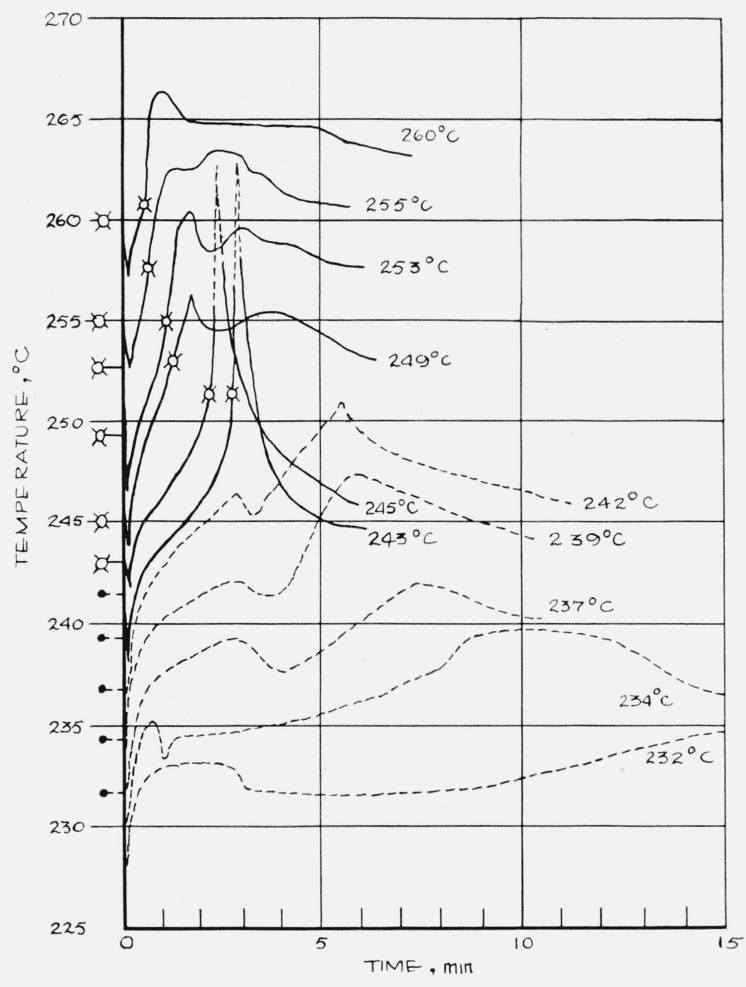

Figure 10. Time-temperature curves for cleaner's solvent. 1-liter flask, charge equals $0.25 \mathrm{ml}$.

\section{e. Diesel Fuels}

The physical properties of four Diesel fuels, and their ignition characteristics determined in the 1liter flask, are given in table 6 .

The time-temperature curves of figure 11 are representative for these fuels. The two upper curves were obtained for a straight-run fuel (55 cetane); the two lower curves were obtained with the same fuel, to which 1 percent of ethyl nitrate had been added. A small addition of the accelerator reduced the ignition temperature from $230^{\circ}$ to $226^{\circ} \mathrm{C}$, and the ignition lag from $2 \frac{1}{2} \mathrm{~min}$ to $1 \frac{3 / 4}{4} \mathrm{~min}$, and the intensity of ignition changed from explosion to normal flame.

TAвLE 6. Physical properties and ignition characteristics of Diesel fuels

\begin{tabular}{|c|c|c|c|c|}
\hline Property & \multicolumn{4}{|c|}{ Fuel- } \\
\hline Cetane number. & 41. & 55 & 60 & 68. \\
\hline Production method. & Cracked distillate & Straight run & Straight run & $\begin{array}{l}55 \text { cetane with } \\
\text { combustion ac- } \\
\text { celerator. }\end{array}$ \\
\hline Specific gravity _._. & 33.7 & 32.8 & 38.3 & 38.2 \\
\hline Viscosity, Saybolt & 34.7 & 50.4 & 43.0 & 36.2 . \\
\hline Flash point & 185 & 213 & 151 & 130. \\
\hline Boiling point & 405 & 415 . & 323 & 221 . \\
\hline Sulphur content & $0.29_{-}$ & 0.23 & $0.10_{-}$ & 0.14 \\
\hline SIT $\ldots$ & 233 & 230 & 225 & 226. \\
\hline Ignition lag & $3: 00$ & $2: 30$ & $2: 30$ & $1: 45$. \\
\hline Evidence $^{\mathrm{a}} \ldots$ & $1 \ldots$ & $5 \ldots$ & $4 \ldots$ & 3. \\
\hline
\end{tabular}

a Key for evidence of ignition: 1, Mild flame; 3 , flame; 4, mild explosion; 5, explosion. 


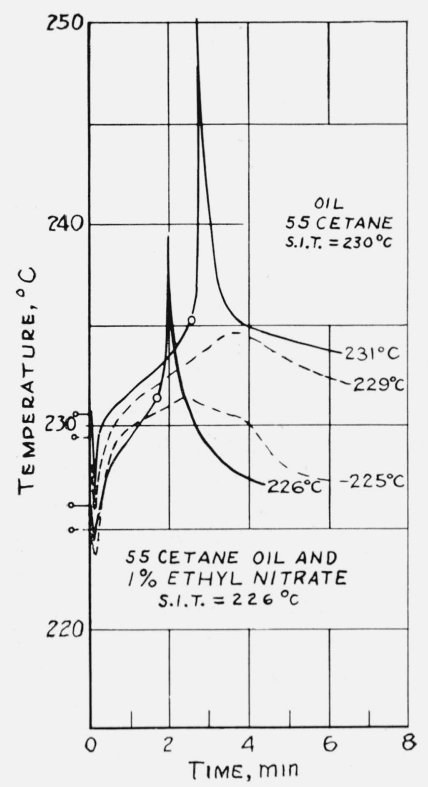

Figure 11. Effect of ethyl nitrate on the SIT of diesel oil. 1-liter flask, charge equals $0.2 \mathrm{ml}$.

\section{f. Furnace Oil No. 2}

The general ignition characteristics of furnace oil No. 2 were substantially the same as those of Diesel fuels of 41 and 55 cetane number, i. e., single-stage reaction with medium self-heating before ignition, which occurred at $233^{\circ} \mathrm{C}$, with mild flame after $2 \min 40$ sec.

\section{g. Lubricating Oils}

Lubricating oils generally represent a complex mixture of different hydrocarbon components having different affinity for oxygen. Because of this, the self-ignition of oil vapor does not always proceed in a definite order, or as consistently as in the case of other combustible liquids. Oils having a comparatively low ignition temperature, such as U. S. Navy Nos. 2075 and 8190, ignited in a more or less definite and reproducible manner. However, chlorinated paraffin oils and motor lubricating oils used for internal-combustion engines usually showed irregular ignition in the zone of minimum ignition temperatures. Above this zone, ignition was observed regularly, and below it the oil vapors were definitely not ignitible. For chlorinated paraffin oil this doubtful zone covered a range of about $10 \operatorname{deg} \mathrm{C}$, but for motor oil it amounted to about $35 \mathrm{deg} \mathrm{C}$, as indicated in figure 12 .

The reasons for this irregularity of ignition were not established. However, from observation of the reacting mixture under a strong light directed through the pyrex cover over the neck of the flask, it appeared that poor distribution of the charge may have been largely responsible. As these oils were sprayed into the reaction chamber, they formed dense clouds that required an appreciable time to become well mixed with the air throughout the
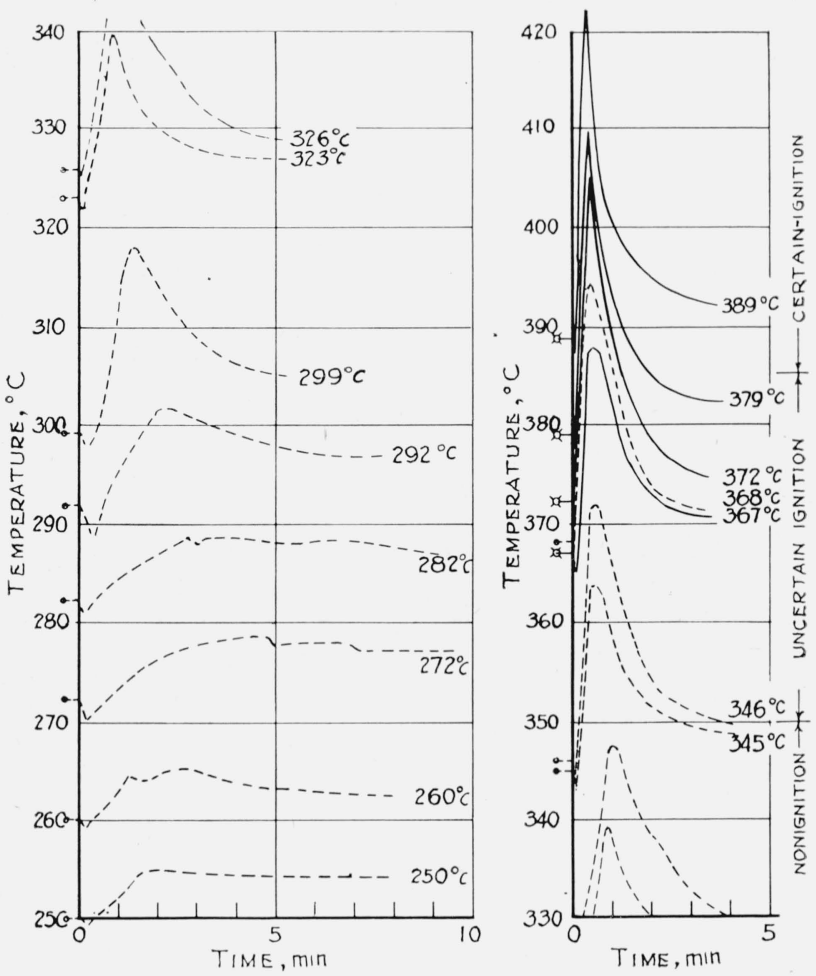

FIgURE 12. Time-temperature curves for motor lubricating oil. 1-liter flask, charge equals $0.2 \mathrm{ml}$.

chamber. In this nonuniform mixture there was a tendency for ignition to take place in small local areas. At relatively high initial temperatures, such local ignition was commonly followed by multiple ignitions in other parts of the chamber, but at lower initial temperatures, a partial ignition frequently occurred without sufficient violence to affect the remainder of the mixture. Moreover, the dense clouds of unburned oil tended to obscure the evidence of a mild ignition, even when viewed under darkroom conditions, and detection was sometimes uncertain. These variable conditions could be expected to produce irregular ignition results in the temperature range near the SIT. It was noted, furthermore, that the irregularities became more pronounced as richer reaction mixtures or larger flasks were used, a situation particularly susceptible to nonuniform distribution of the charge.

\section{h. Benzene}

The time-temperature curves obtained for pure benzene $\left(\mathrm{C}_{6} \mathrm{H}_{5}\right)$ are shown in figure 13. Appreciable self-heating of the reacting mixture was observed $50 \mathrm{deg} \mathrm{C}$ below the self-ignition temperature. At the initial temperature of $557^{\circ} \mathrm{C}$, the mixture selfheated to $690^{\circ} \mathrm{C}$. However, at the initial temperature of $565^{\circ} \mathrm{C}$, actual ignition was observed at $603^{\circ} \mathrm{C}$, or about $87 \mathrm{deg} \mathrm{C}$ below the maximum temperature of the preceding test. Here, again, evidence is presented of the fact that the initial temperature from which the exothermic reaction proceeds to ignition is more significant than the 


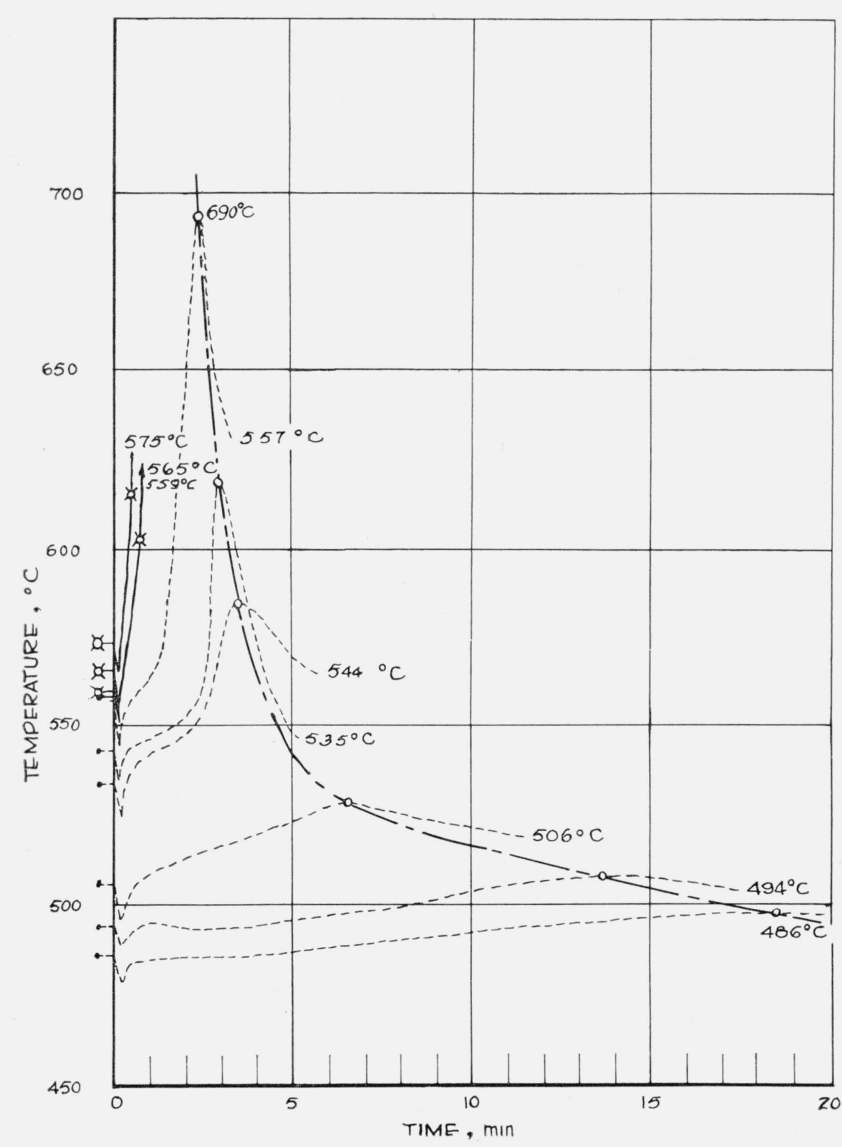

Figure 13. Time-temperature curves for benzene. 1-liter flask, charge equals $0.2 \mathrm{ml}$. temperature of the reacting mixture at the instant of ignition. It is interesting to note that the maximum temperatures for each reaction fall on a smooth curve. The shape of the nonignition reaction timetemperature curve is similar to, but not identical with, that of single-stage reactions of other materials. Although both the ignition and nonignition reactions were characterized by rapid increases in temperature, ignition was indicated by a barely audible expulsion of dense smoke and mild flame.

\section{i. Toluene}

The self-heating and ignition characteristics of toluene were similar to those of benzene, and timetemperature curves of substantially the same type were obtained.

\subsection{Petroleum Compounds}

Three groups of hydrocarbon compounds derived from petroleum, were supplied by the division of thermochemistry. The ignition characteristics of these hydrocarbons were determined in the 1-liter apparatus, and are given in table 7 .

\section{a. Normal Paraffins}

Figure 14 gives representative time-temperature curves for fractions of the chain type, which showed substantially the same behavior, with the exception of dodecane and cetane, the nonignition reactions of which had a retarding portion similar to a twostage reaction. The rate of the inducing reaction preceding ignition gradually decreased, and the ignition lag increased with the carbon content.

TABLE 7. Physical properties and ignition characteristics of petroleum compounds

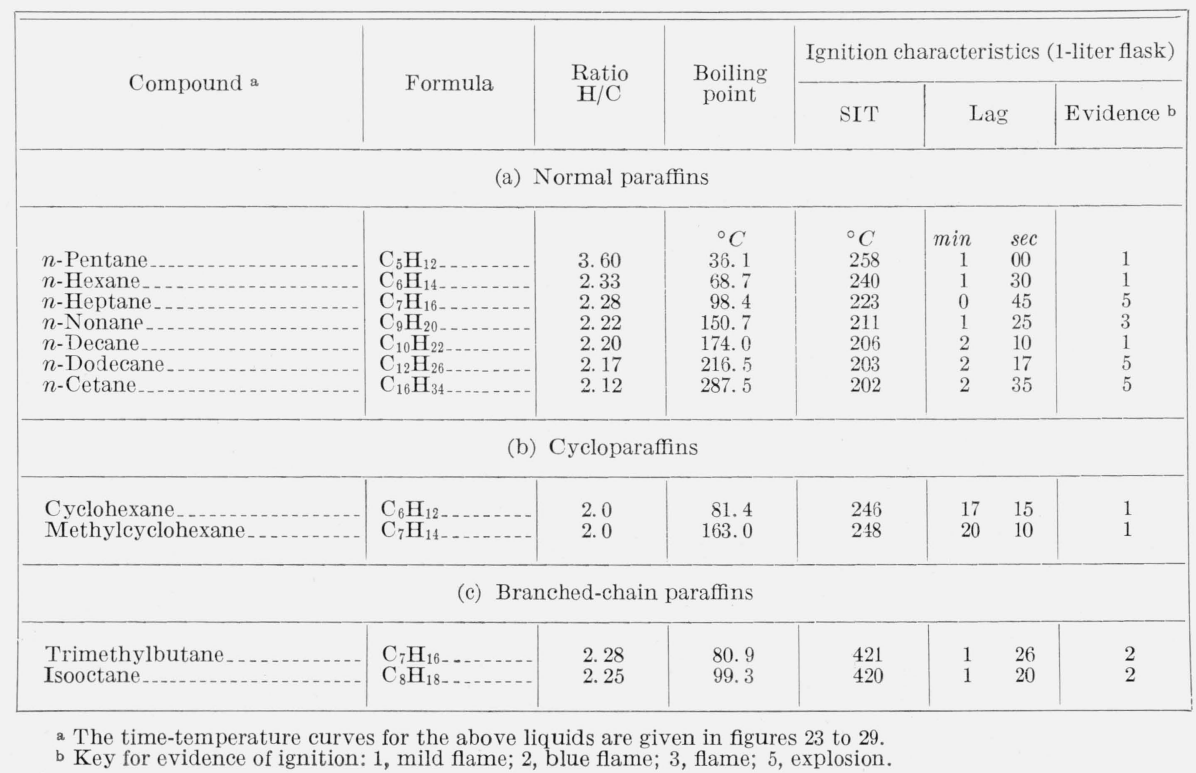



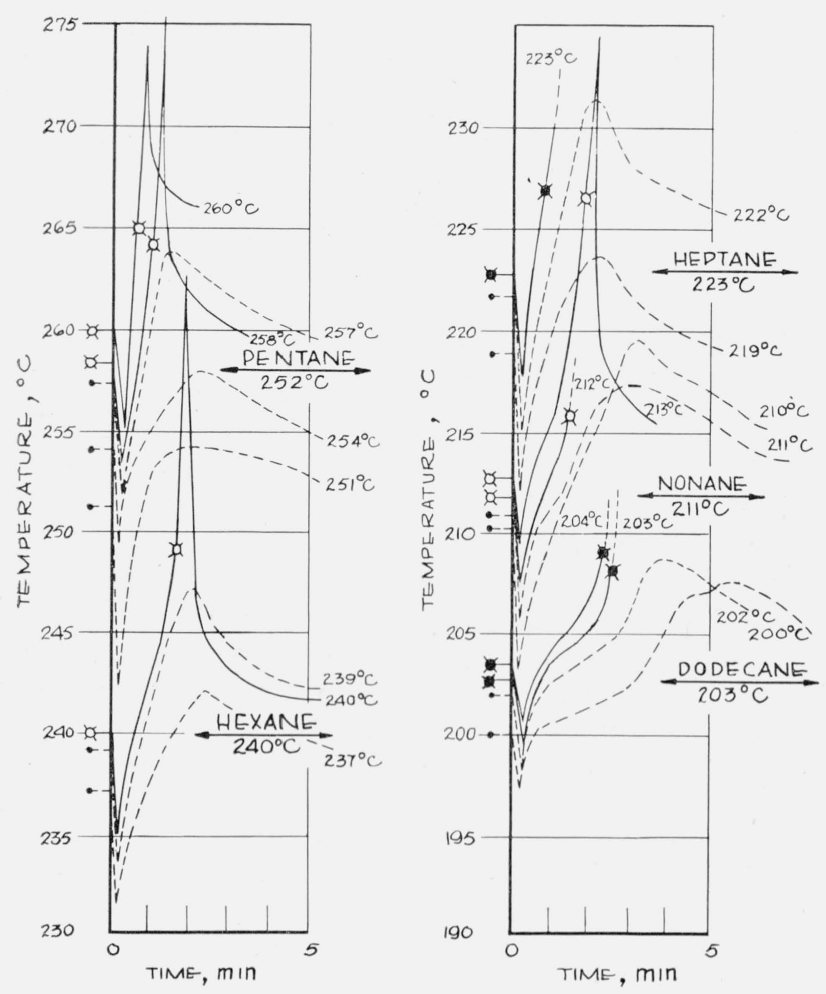

FIGURE 14. Time-temperature curves for some normal paraffins. 1-liter flask.

The self-ignition temperature of liquids of the chain type consistently diminished with an increasing number of carbon atoms up to $16\left(\mathrm{C}_{16} \mathrm{H}_{34}\right)$, as shown in figure 15. The curve for fractions of larger carbon content was not determined because of limited quantities of rare fractions. However, tests of very small amounts of dotriacontane $\left(\mathrm{C}_{32} \mathrm{H}_{66}\right)$ indicated the self-ignition temperature to be somewhere above $300^{\circ} \mathrm{C}$. In other words, it would appear that the curve must turn upward after carbon 16. Additional tests will be necessary to confirm the shape of this curve.

\section{b. Cycloparaffins}

The time-temperature curves for cyclohexane and methylcyclohexane, the two ring type fractions tested, were similar. Curves for methylcyclohexane are shown in figure 16 . It will be noted that the reaction appeared to be of a two-stage type, with an extended period of constant temperature before the rapid heating of the second stage began. Ignition took place during the second stage, and, as the initial temperature was raised, the delay between stages was gradually eliminated. The two-stage pattern of reaction for cyclohexane is nearly identical with the patterns obtained for motor and aviation gasolines in the same region of initial temperatures.

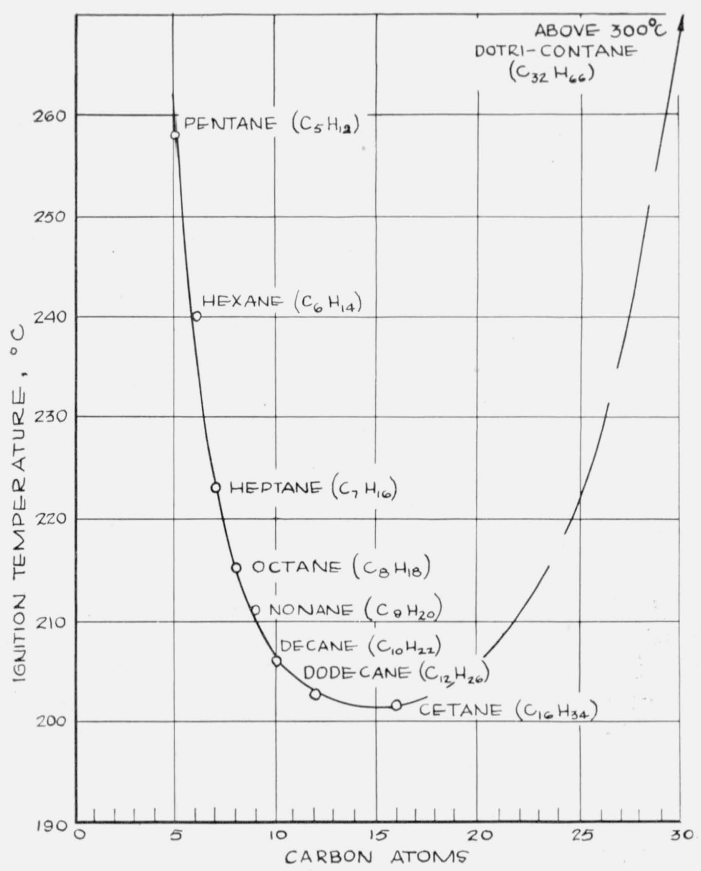

Figure 15. Relation between SIT and carbon content of normal paraffins.

1-liter flask.

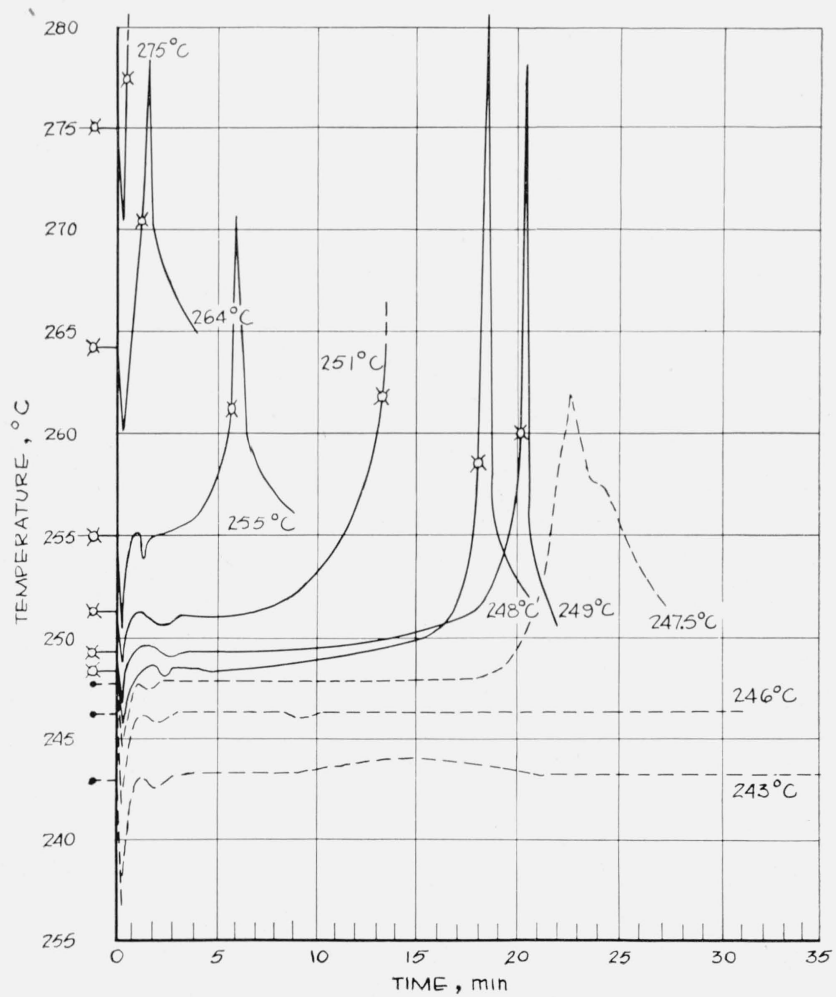

FIgURE 16. Time-temperature curves for methylcyclohexa ne $\left(\mathrm{C}_{7} \mathrm{H}_{14}\right)$.

1-liter flask, charge equals $0.2 \mathrm{ml}$ 


\section{c. Branched-Chain Paraffins}

Trimethylbutane (Triptane). As the minimum self-ignition temperature of this compound was approached, the visible and audible evidences of ignition became weak, and precise determination of the SIT was difficult. Furthermore, the timetemperature curves for ignition and nonignition reactions had substantially the same shape. However, at an initial temperature of $421^{\circ} \mathrm{C}$ the reaction definitely proceeded to ignition with a blue-violet flame. At lower temperatures light produced by the reacting mixture appeared to be that of a cool flame reaction.

Isooctane (2,2,4-Trimethylpentane). The ignition characteristics of isooctane (and difficulties of ignitiontemperature determination) were similar to those for trimethylbutane. The observed reproducibility of blue flame, or cool flame, was very poor and was affected by deposits on the flask wall, by direction of the charge stream, and by relative humidity of the air. Injection of the charge along the side of the neck wall usually stimulated ignition at slightly lower temperatures than injection directly to the bottom of the flask. Self-ignition temperatures obtained at different times ranged from $408^{\circ}$ to $425^{\circ} \mathrm{C}$. The value of $420^{\circ} \mathrm{C}$ (with corresponding ignition lag of $1 \mathrm{~min} 20 \mathrm{sec}$ ) recorded in table 7 was fairly reproducible.

Although these difficulties were encountered with all sizes of flasks used, reproducibility of the determinations was slightly better in the 0.2 and 12 -liter flasks than in the 1-liter flask. The band of uncertainty in the 0.2-liter flask was no more than $12 \operatorname{deg} \mathrm{C}$, and in the 12 -liter flask it was reduced to $4 \operatorname{deg} \mathrm{C}$.

\subsection{Reference Fuels}

The reference fuels commonly used in determining the knock ratings of motor fuels comprise variously proportioned mixtures of isooctane and $n$-heptane. Essentially the rating procedure consists in determining what mixture most closely matches the performance of the fuel under study, using a standard CFR (Cooperative Fuel Research Committee) engine operated under specified conditions. The percentage of isooctane in this mixture is taken as the octane number of the fuel being tested. Details of the procedure differ with the purpose of the fuel, and the AS'TM has established four different methods (motor, research, aviation, and supercharged) for gasolines, and one for Diesel fuels. The rating of a particular fuel may vary appreciably with the method used, and it is therefore necessary to consider the method of determination when knock ratings are used as a basis of comparison.

The ignition characteristics of these primary reference-fuel mixtures were studied in the regular 1-liter test apparatus, and time-temperature curves for a number of them are shown in figure 17. In addition two other types of mixtures, formerly used as secondary reference fuels were also tested. These secondary reference fuels were prepared from three specific fuels, and consisted of (1) mixtures of fuel $\mathrm{A}_{6}$ with fuel $\mathrm{C}_{12}$, and (2) mixtures of fuel $\mathrm{C}_{12}$ with fuel $\mathrm{F}_{3}$. Although improved methods of manufacture and reduced cost of the primary reference fuels have now eliminated the need for intermediate standards, investigation of the well-defined secondary reference fuels were of interest at the time the tests were performed.

In figures 18 and 19 the data obtained for primary and secondary reference-fuel mixtures, respectively, have been plotted to show the effect of change in composition on different ignition characteristics. With increasing isooctane content, up to about 70 percent, the SIT of the primary reference-fuel mixtures increased gradually and continuously, and the ignition was marked by the characteristic red flame of $n$-heptane. The intensity of ignition changed gradually from explosion to mild flame as the isooctane content increased. With isooctane concentrations of 50 percent and higher an audible expulsion of gases without flame was observed at temperatures below ignition, and this "puff" also diminished in intensity as the concentration of isooctane increased. At 70 percent isooctane, the SIT-composition curve showed a break; mixtures containing more than 70 percent of isooctane igniting only at decidedly higher temperatures, and generally with the blue flame and considerable variability noted previously for pure isooctane. Ignition was somewhat erratic also in mixtures of slightly less than 70 percent isooctane content, forming a so-called "secondary nonignition zone" similar to those observed by Prettre [15] with pentane and hexane by Townend [16] with hexane, by Sortman and Beatty [5] with heptane and cetane, and by many other investigators. The fact that nonignition zones with these latter liquids were not observed in the present investigation suggests that the appearance of such zones may be a function of the test apparatus and conditions rather than of the material under study.

The series of secondary reference-fuel mixtures prepared from fuels $\mathrm{A}_{6}$ and $\mathrm{C}_{12}$ showed a continuous linear increase in ignition temperature with increasing $\mathrm{C}_{12}$ content as indicated in curve II of figure 19 . The series of mixtures of fuels $\mathrm{C}_{12}$ and $\mathrm{F}_{3}$, however, gave a pattern of ignition behavior (curve III) similar to that obtained for the primary referencefuel mixtures, including a secondary nonignition zone and the "puff" without flame at temperatures below ignition for mixtures rich in the component having the higher ignition temperature.

In order to indicate the degree of correlation between self-ignition temperature and motor-method octane number, SIT - octane-number curves were plotted for both the primary and secondary reference-fuel mixtures. In addition, self-ignition temperature determinations were made on three other gasolines of known octane number. Of the secondary reference fuels, only the end fuels $A_{6}$ and $F_{3}$ showed substantially the same SIT values as the primary reference fuels of corresponding octane 

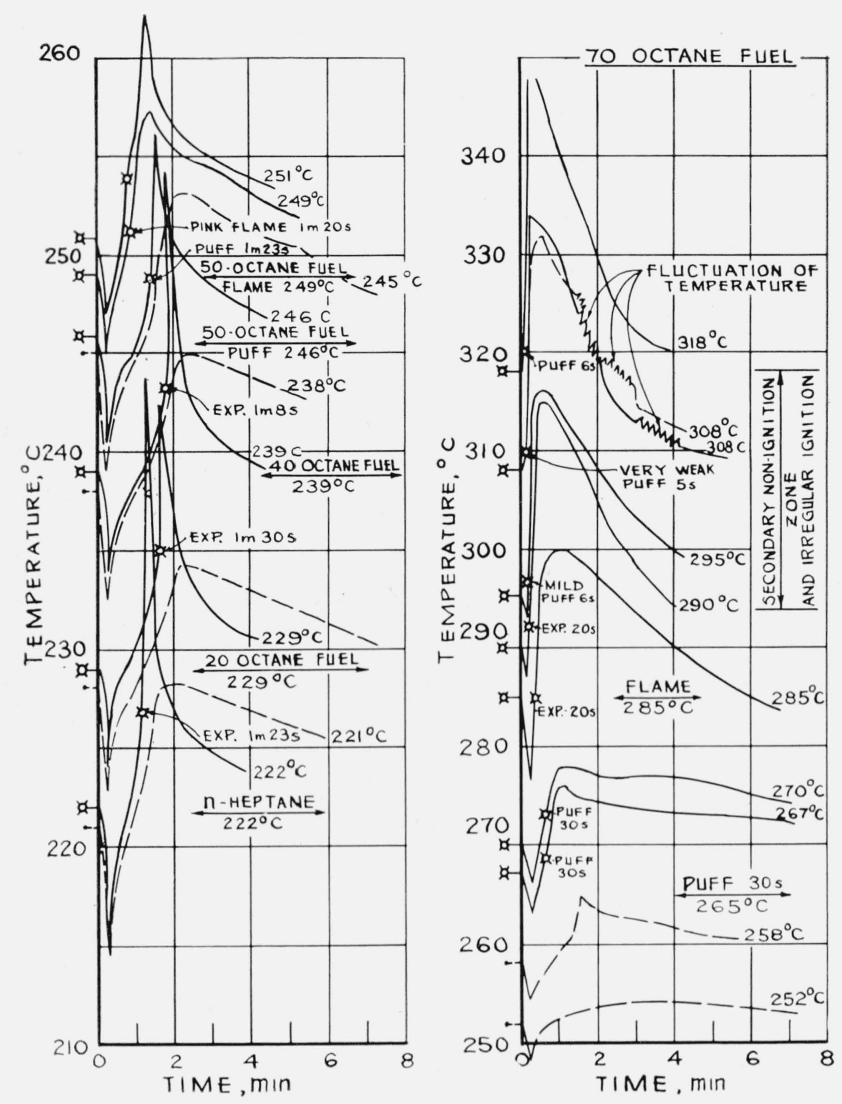

FIGURE 17. Time-temperature curves for primary reference fuels.

1-liter flask.

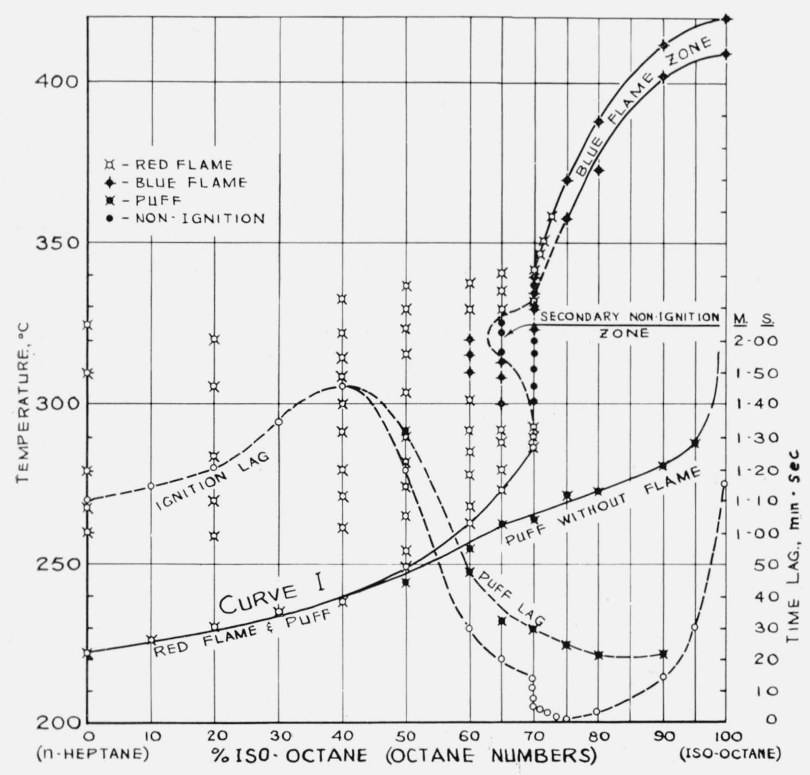

FIgURE 18. Relation between SIT and composition of primary reference fuels.

1-liter flask.

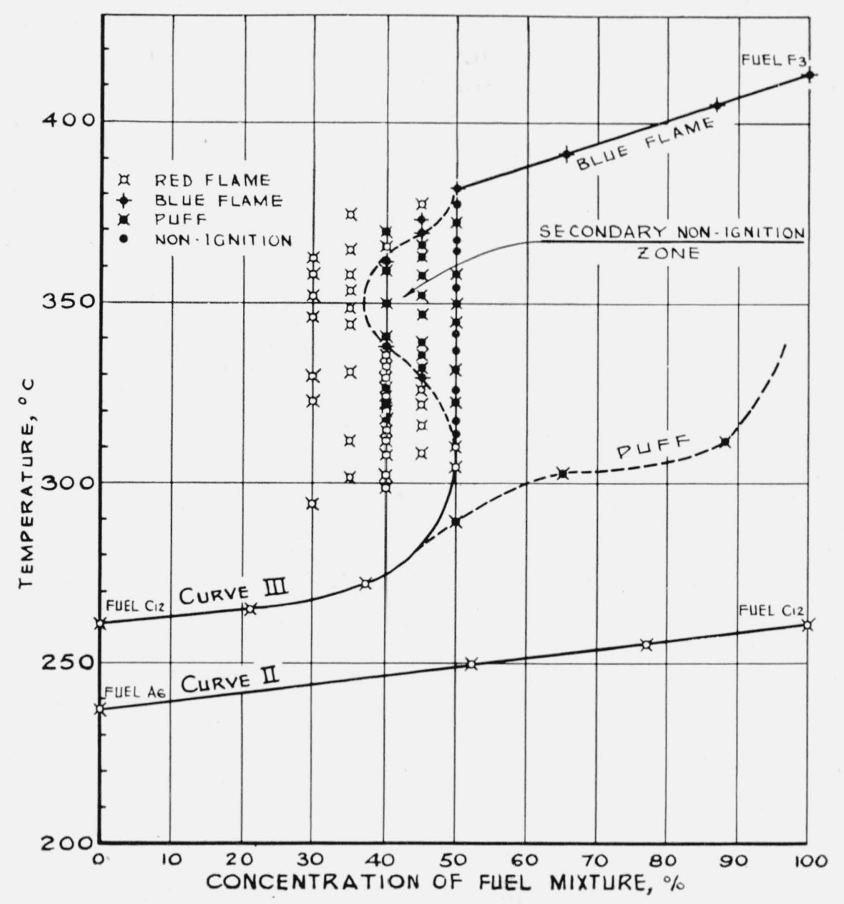

FIgURE 19. Relation between SIT and composition of secondary reference fuels.

1-liter flask.

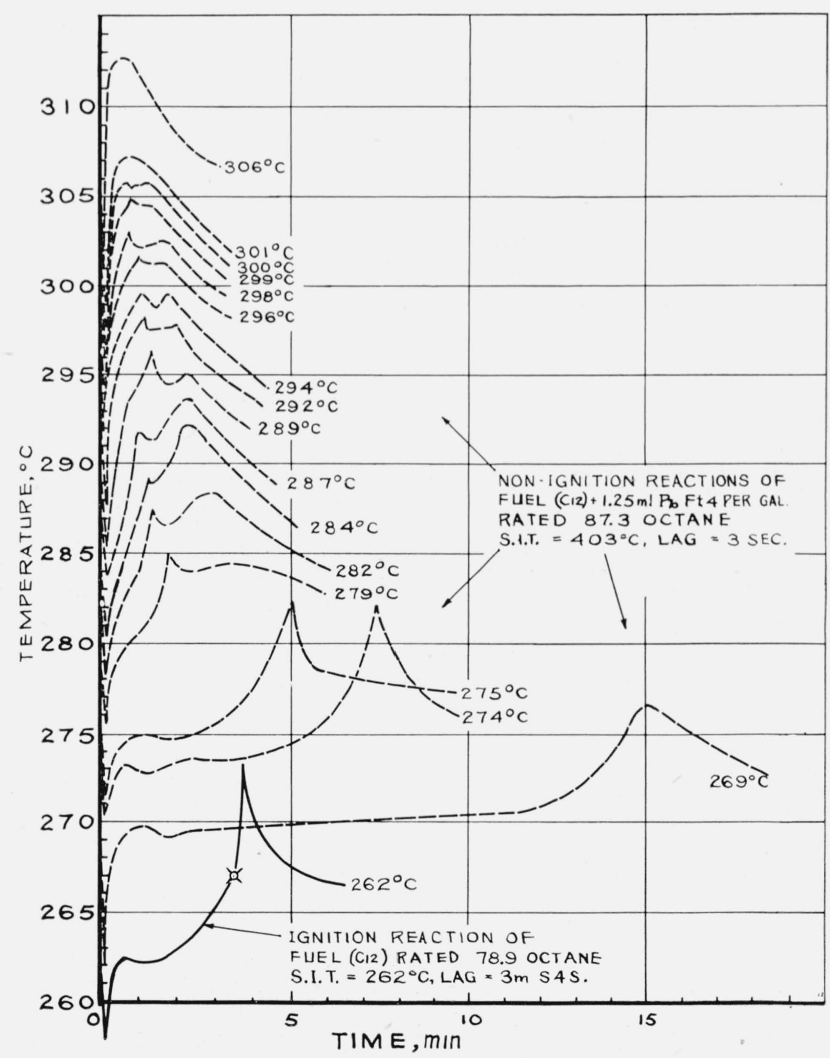

FIGURE 20. Effect of a combustion accelerator on the timetemperature curves of fuel $\mathrm{C}_{12}$.

1 -liter flask, charge equals $0.2 \mathrm{ml}$. 
numbers. Only one of the three additional gasolines tested gave an SIT value approximately the same as that of the primary reference fuel of corresponding octane number. Similar poor correlation between ignition characteristics and octane-number ratings have been noted by other investigators with other test apparatus (Jentzsch Eckert Zerbe and Carhart).

The effects of a small amount of ethyl fluid additive on the ignition characteristics of a fuel were also studied. A typical time-temperature curve for the ignition of fuel $\mathrm{C}_{12}$ (78.9 octane number) is shown in the lower part of figure 20. The broken-line curves in the upper part of the figure are time-temperature curves for nonignition reactions, at increasing initial temperatures, of the same fuel with $1.25 \mathrm{ml}$ of tetraethyl lead added per gallon. The shape of these curves changed entirely, and many additional stages of reaction developed before the reaction finally accelerated to ignition.

\subsection{Miscellaneous Compounds}

The SIT values obtained in the 1-liter flask for seven miscellaneous liquids are given in table 8 . The effect of varying the flask size is shown for several of them in table 3.

For all except methyl alcohol, both the ignition and nonignition reactions were characterized by an immediate rapid acceleration, as illustrated by the curves for acetone shown in figure 21. With methyl alcohol (fig. 22), the acceleration was somewhat delayed, and the curves for ignition and nonignition reactions differed distinctly in shape. Additional comments on the reaction characteristics of the individual liquids follow.

TABLE 8. Ignition characteristics of miscellaneous compounds determined in the 1-liter flask

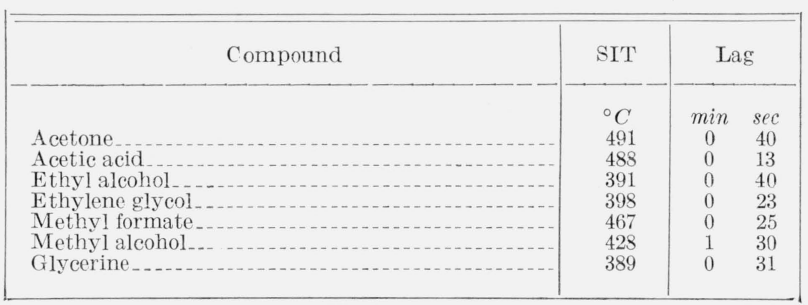

\section{a. Acetone}

At the minimum self-ignition temperature, acetone ignited with a blue-violet light, often initiated at and spreading from a small, red, glowing center of carbonized deposit of acetone on the flask wall. The light usually appeared without audible manifestation and continued to be visible for about 20 seconds at $491^{\circ} \mathrm{C}$ and about 15 seconds at $505^{\circ} \mathrm{C}$. The nature of this light gradually changed from dull blue-violet at $491^{\circ} \mathrm{C}$ to blue-pink at $515^{\circ} \mathrm{C}$ and to a pink-violet flash with an audible explosion at higher temperatures. The initial blue-violet light was similar to

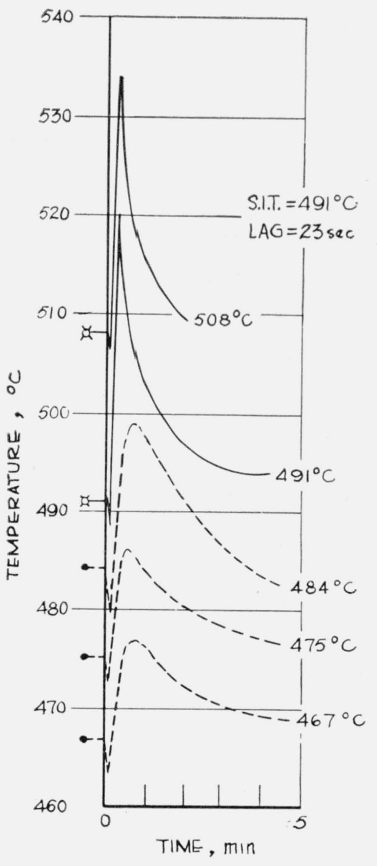

Figure 21. Time-temperature curves for acetone. 1-liter flask, charge equals $0.2 \mathrm{ml}$.

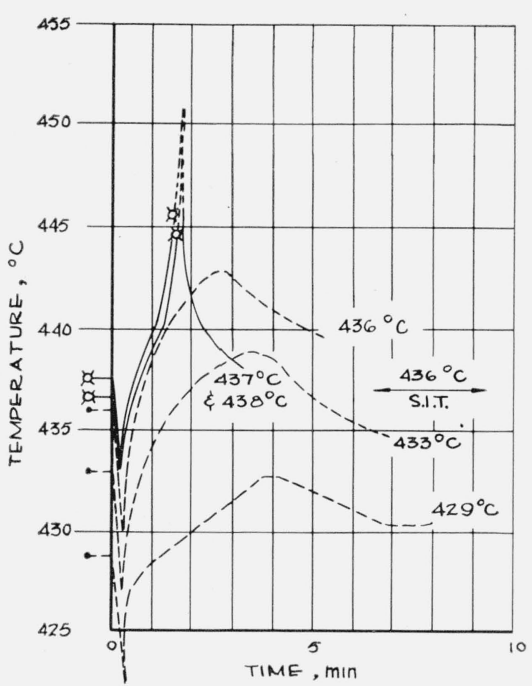

FIGURE 22. Time-temperature curves for methyl alcohol. 1-liter flask, charge equals $0.2 \mathrm{ml}$.

that of a cool flame, and when first observed it was questioned whether this could be taken as an indication of ignition. However, in consideration of the very sharp increase in the time-temperature curve (fig. 21) at $491^{\circ} \mathrm{C}$, this temperature was taken as the self-ignition temperature. 


\section{b. Acetic Acid}

Ignition of acetic acid occurred so irregularly that it was difficult to define the lowest self-ignition temperature. One possible explanation of such irregularity may lie in the ability of acetic acid to exist in two interchangeable states, "dimer" and "monomer", expressed by the relationship

\section{$\left(\mathrm{CH}_{3} \mathrm{COOH}\right)_{2} \rightleftarrows 2 \mathrm{CH}_{3} \mathrm{COOH}$.}

The two forms may have different ignition temperatures, and uncontrolled variables might have caused a shift from one form to the other.

Ignition of acetic acid, in spite of the irregularity of occurrence, was distinctly defined by audible and visible evidence, and usually occurred about 8 seconds after injection of the charge. Ignition was initiated with a blue flame, which, at the end of the ignition period, changed to a pink color. This pink color, however, might have been due to reflection of the dull-red furnace walls from fog formed within the chamber. Although the mixture remained clear and transparent throughout most of the reaction, there was some evidence of the development of fog toward the end of the exothermic reaction.

\section{c. Ethyl Alcohol}

Due to the rapid increase of pressure at the time of evaporation, an audible expulsion of gases was observed before ignition. The actual ignition, at $391^{\circ} \mathrm{C}$ after 40 seconds, was accompanied by blue flame with a second expulsion of gases.

Ethyl alcohol-water mixtures were also found to be readily ignitible. The self-ignition temperature increased from $391^{\circ}$ to $444^{\circ} \mathrm{C}$ as the water content of the mixture approached 70 percent. Very weak flame was observed at $467^{\circ} \mathrm{C}$ even with 80 percent water.

\section{d. Ethylene Glycol}

The ignition of ethylene glycol in the 1-liter flask was indicated at $398^{\circ} \mathrm{C}$ by orange-blue flame and a hardly audible expulsion of gases. However, the same liquid containing 3 percent of an antirusting ingredient (triethanolamine phosphate) ignited at $395^{\circ} \mathrm{C}$ with a violent explosion. Tests on ethylene glycol-water solutions showed ignition of mixtures containing up to 90 percent of water (for which an ignition temperature of $460^{\circ} \mathrm{C}$ was obtained), although with more than 40 percent of water the flame became very weak.

Two other antifreeze liquids, R-19 and R-19d, were tested, and the results indicated that these liquids were highly ignitible. Both liquids were petroleum distillates (kerosine type), liquid R-19 being the product without additive and $\mathrm{R}-19 \mathrm{~d}$ being a mixture of the product with an ingredient reported to prevent the softening of rubber hose in engine installations. The self-ignition temperature of R-19 was $211^{\circ} \mathrm{C}$, with an ignition lag of $3 \mathrm{~min} 50 \mathrm{sec}$; $\mathrm{R}-19 \mathrm{~d}$ ignited at $223^{\circ} \mathrm{C}$ after $1 \mathrm{~min} 30 \mathrm{sec}$. Ignition of both liquids occurred suddenly with a violent explosion when the thermocouple indicated a temperature only $3 \operatorname{deg} \mathrm{C}$ above the initial temperature.

\section{e. Methyl Formate}

Ignition of methyl formate was indicated regularly by a mild explosion and rapid rise in temperature similar to that for acetone (fig. 21).

\section{f. Glycerine}

Glycerine ignited with a violent explosion accompanied by long flame and smoke expelled from the neck of the ignition apparatus. The rise in temperature of the gas mixture immediately after injection of the charge was particularly extreme for both ignition and nonignition reactions.

Observation of the flask interior showed that, immediately after injection of the charge, viscous glycerine droplets accumulated on the bottom surface of the flask and rapidly produced a dense white fog. After about 20 seconds, this fog became clear either due to superheating or partial oxidation. This was followed, usually in about 5 seconds, by the appearance of a small blue flame with a pink center. Due to rapid propagation of flame, gases were expelled from the neck of the flask with considerable force.

$$
\text { g. Methyl Alcohol }
$$

Methyl alcohol showed a mild form of ignition characterized by a dull blue flame and a weak expulsion of clear gas, but the difference in shape of the time-temperature curves for ignition and nonignition reactions (fig. 22) provided supplemental evidence of the definite location of the SIT.

\subsection{Miscellaneous Commercial Materials}

A number of commercially produced combustible materials were tested in the 1-liter ignition apparatus and their ignition characteristics are given in table 9. The time-temperature curves typical of many of these materials were similar to those for acetone (fig. 21).

TABLE 9. Ignition characteristics of miscellaneous commercial materials

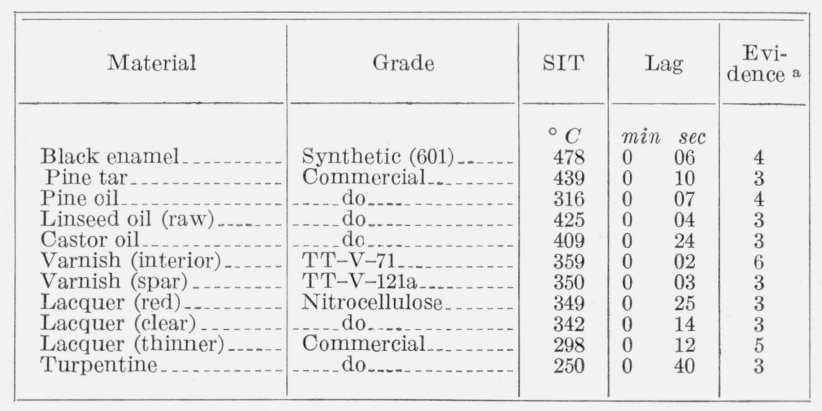

a Key for evidence of ignition: 3, Flame; 4, mild explosion; 5, explosion; 6 violent explosioir. 


\section{a. Black Enamel}

Noticeable decomposition of synthetic black automobile enamel (601) was indicated at $270^{\circ} \mathrm{C}$ by the appearance of smoke. At a temperature of about $445^{\circ} \mathrm{C}$, carbonized residue of the charge self-heated to the glow state. However, self-ignition occurred at $478^{\circ} \mathrm{C}$ with a large flame and audible expulsion of gas and smoke. As a result of ignition, all the carbon residue was burned out and the flask surface became clear.

\section{b. Pine Tar}

Pine tar of commerical grade, due to its low "fluidity", was preheated in boiling water before injection with a hypodermic syringe. The exothermic reaction began far below the ignition temperature and ignition was indicated by flame and a mild expulsion of smoke. The flask surface, after ignition, was usually covered by a brownish coating and tar residue, baked to a hard carbon deposit removable only with a scraper. However, with pine oil the residue after ignition was soft and easily removable from the surface.

$$
\text { c. Linseed Oil }
$$

The ignition characteristics of linseed oil were similar to those of lubricating oils, and appreciable self-heating of the vapor-air mixture was observed at temperatures far below the ignition temperature.

\section{d. Varnish and Lacquer}

The reaction characteristics of varnish and lacquers were substantially the same, particularly in the nonignition region. Self-heating of the vapor-air mixture was initiated far below the self-ignition temperature, and often amounted to 20 to $25 \mathrm{deg} \mathrm{C}$ in nonignition reactions near the self-ignition temperature. Ignition of these liquids, with the exception of interior varnish and lacquer thinner, was very mild; both the lacquer thinner and interior varnish ignited with an audible explosion.

\section{e. Turpentine}

The time-temperature curves for turpentine were similar to those for kerosine, having the same twostage nonignition reaction with ignition definitely in the first stage.

\section{Summary}

The apparatus and method described for the determination of self-ignition temperatures is practical and readily adaptable to combustible liquids of widely different physical and chemical properties. Data on a considerable number of liquids are presented.

Time-temperature curves of a thermocouple junction in mixtures of combustible liquid and air, offer a convenient means of studying the preignition reactions in such mixtures. Typical time-temperature curves are given.
The importance of careful standardization of equipment and procedure in obtaining reproducible results has been demonstrated. Thus, for reaction vessels of similar construction, the self-ignition temperature was found to decrease with increase in size of the chamber, over the capacity range studied, with differences as high as $200 \mathrm{deg} \mathrm{C}$ being obtained in vessels of 0.008 -and 12 -liter capacity. With Pyrex reaction chambers of the same size but with different exterior casings, variations up to nearly 30 $\operatorname{deg} \mathrm{C}$ were observed in the determined self-ignition temperature. In view of the effects produced by these modifications of equipment within a single method, the large discrepancies in ignition temperatures reported by different investigators using various methods are not surprising.

The ignition temperatures measured with the apparatus described are lower than those reported by most other workers.

The author is indebted to M. Sandholzer for assistance in the preparation of this paper.

\section{References}

[1] T. T. S. Sebastian and M. A. Mayers, Ind. Eng. Chem. 29, 1118 (1937)

[2] C. R. Brown, The determination of the ignition temperature of solid materials (Doctoral Thesis, Catholic Univ. of America 1934).

[3] H. Holm, Z. Angew. Chem. 26, 273 (1913).

[4] H. Moore, J. S. C. I. 36, 109 (1917); J. I. P. T. 6, 186 (1920).

[5] C. W. Sortman and H. A. Beatty, Ind. Eng. Chem. 33, 357 (1941)

[6] H. Jentzsch, Z. Ver. deut. Ing. 68, 1150 (1924); 69, 1353 (1925).

[7] D. M. Newitt and D. T. A. Townend, The Science of Petroleum, vol. IV, p. 2958 (1938).

[8] H. B. Dixon and H. F. Coward, J. Chem. Soc. 98, 514 (1909).

[9] H. B. Dixon and H. F. Coward, J. Chem. Soc. P. 1382 (1934).

[10] W. Mason and R. V. Wheeler, J. Chem. Soc. 121, 2079 (1922); 125, 1869 (1924).

[11] H. L. Callendar, Engineering 123, 147 (1927).

[12] C. Moureu, Chim. et Ind. 18, 3 (1927); Compt. rend. 185, 1545 (1927).

[13] S. M. Estradére, Pub. Tech. of Ministry of Air (Paris), No. 49 (1934).

14] S. J. Lewis, J. Chem. Soc. p. 1555 (1927); p. 58 and 2241 (1930).

[15] M. Prettre, The Science of Petroleum, vol. IV, p. 2951 (1938).

[16] D. T. A. Townend, Proc. Roy. Soc. 141A, 484 (1933); 143A, 168 (1933); 146A, 113 (1934).

[17] L. M. Pidgeon and A. C. Egerton, J. Chem. Soc. p. 661, 676 (1932)

[18] Neumann, Z. Ver. deut. Ing. 70, 1071 (1926); NACA Tech. Mem. 391 (Dec. 1926).

[19] H. T. Tizard and D. R. Pye, Auto. Eng. 13, 136 (1923).

[20] A. Pignot, Compt. rend. 182, 376 (1926).

[21] ASTM Standard Method, ASTM Standards, pt. 5, 147 (1952).

[22] L. F. Mareck and D. A. Hahn, Catalytic oxidation of organic compounds in vapour phase, Chem. Soc. Monograph Series (Chemical Catalog Co., N. Y., 1932), p. 311.

[23] H. L. Callendar, Engineering 125, 183 (1927).

[24] N. J. Thompson, Ind. Eng. Chem. 21, 134 (1929).

[25] A. F. Matson and R. E. Dufour, Underwriters' Laboratories, Inc., Bul. of Research No. 43 (1950).

Washington, March 5, 1954. 